\title{
Neuronal Dystroglycan regulates postnatal development of CCK/cannabinoid receptor-1 interneurons
}

\section{Daniel S. Miller ${ }^{1}$ and Kevin M. Wright ${ }^{2, \#}$}

${ }^{1}$ Neuroscience Graduate Program, Oregon Health \& Science University, Portland, OR 97239, USA

${ }^{2}$ Vollum Institute, Oregon Health \& Science University, Portland, OR 97239, USA

\#Correspondence:

Kevin M. Wright

Vollum Institute

Oregon Health \& Science University

VIB 3435A

3181 SW Sam Jackson Park Road

Portland, OR 97239-3098

1-503-494-6955

wrighke@ohsu.edu

Running title: Dag1 controls CCK+ IN development

Number of Pages: 57

Number of Figures: 9

Number of words: Abstract (158), Introduction (807), Discussion (2334)

The authors declare that they have no competing interests.

\section{Acknowledgments}

This work was funded by NIH Grants R01-NS091027 (K.M.W.), CureCMD (K.M.W.), NINDS P30-NS061800 (OHSU ALM), NINDS F31 NS108522 (D.S.M), and a Tartar Trust Fellowship (D.S.M). 


\section{ABSTRACT}

2 The development of functional neural circuits requires the precise formation of synaptic

3 connections between diverse neuronal populations. The molecular pathways that allow

4 GABAergic interneuron subtypes in the mammalian brain to recognize their

5 postsynaptic partners remain largely unknown. The transmembrane glycoprotein

6 Dystroglycan is localized to inhibitory synapses in pyramidal neurons, where it is

7 required for the proper function of $\mathrm{CCK}+$ interneurons. We show that deletion of

8 Dystroglycan from pyramidal neurons selectively impairs CCK+ interneuron

9 development during the first postnatal week. In the absence of postsynaptic

10 Dystroglycan, presynaptic CCK+ interneurons fail to elaborate their axons and largely

11 disappear from the cortex, hippocampus, amygdala, and olfactory bulb. Bax deletion did

12 not rescue $\mathrm{CCK}+$ interneurons, suggesting that they are not eliminated by canonical

13 apoptosis in Dystroglycan mutants. Rather, we observed an increase in CCK+

14 interneuron innervation of the striatum, suggesting that the remaining $\mathrm{CCK}+$

15 interneurons re-directed their axons to neighboring areas where Dystroglycan

16 expression remained intact. Together these findings identify Dystroglycan as a critical

17 regulator of $\mathrm{CCK}+$ interneuron development.

19 Keywords: Dystroglycan, cannabinoid receptor, cholecystokinin, interneuron, synapse,

20 apoptosis 


\section{BACKGROUND}

25 Proper function of neural circuits requires precise connections between specific

26 populations of excitatory pyramidal and inhibitory neurons. GABAergic interneurons are

27 a highly diverse group of neurons that control brain function by synchronizing and

28 shaping the activity of populations of excitatory pyramidal neurons (PyNs) (Harris et al,

29 2018; Kepecs and Fishell, 2014; Lim et al., 2018; Paul et al., 2017; Pelkey et al., 2017).

30 In mice and humans, the majority of interneurons in the cortex and hippocampus are

31 produced in the medial and caudal ganglionic eminences (MGE and CGE) of the ventral

32 forebrain, and migrate long distances to their final destinations (Anderson et al., 1997;

33 Tamamaki et al., 1997; Zecevic et al., 2010). The importance of interneurons for brain

34 function is underscored by their involvement in a wide variety of neurodevelopmental

35 and neurological disorders including autism, schizophrenia, seizures, and Alzheimer's

36 disease (Chao et al., 2010; de Lanerolle et al., 1989; Lewis et al., 2005; Verret et al., 37 2012). development relies on multiple processes such as proliferation, migration, axon guidance, cell death, synaptic target selection, synapse formation (synaptogenesis) and

41 synaptic maintenance. Although much progress has been made in identifying candidate

42 molecules that regulate inhibitory synaptogenesis, our understanding of how

43 molecularly defined subtypes of inhibitory interneurons initially identify specific

44 postsynaptic target cells is lacking (Sanes and Zipursky, 2020; Sudhof, 2018). One

45 prominent hypothesis for explaining how diverse interneuron subtypes recognize one

46 another during synapse development is the "molecular code" hypothesis, whereby 
47 different cell types use unique pairs or complexes of cell adhesion molecules to select

48 their target cells (de Wit and Ghosh, 2016; Foldy et al., 2016; Krueger-Burg et al., 2017;

49 Lu et al., 2017). Cell adhesion molecules are ideally suited to regulate synaptic target

50 recognition due to their large diversity and presence at pre- and postsynaptic

51 membranes. Several recent studies support the idea that cell adhesion molecules are

52 key players in regulating subcellular targeting and synaptic specificity (Anderson et al.,

53 2017; Favuzzi et al., 2019; Sando et al., 2019; Tai et al., 2019). Although many families

54 of cell adhesion molecules have been implicated in controlling synapse development,

55 they are often involved in multiple aspects of neural circuit development, making it

56 difficult to determine their precise role in mediating synaptic specificity.

57 Dystroglycan is a cell adhesion molecule widely expressed throughout the body

58 including the developing and adult brain. Dystroglycan is extensively glycosylated, and

59 mutations in at least 19 genes that participate in synthesizing and elongating specific O-

60 mannose sugar chains on Dystroglycan result in a form of congenital muscular

61 dystrophy called dystroglycanopathy, characterized by muscle weakness and

62 neurological defects of varying severity (Barresi and Campbell, 2010; Manya and Endo,

63 2017; Taniguchi-Ikeda et al., 2016). Dystroglycan (Dag1) is expressed by multiple cell

64 types in the developing nervous system, including neuroepithelial cells, astrocytes,

65 oligodendrocytes, and excitatory neurons (Zaccaria et al., 2001; Nickolls and

66 Bonnemann, 2018). Loss of Dystroglycan function in the nervous system phenocopies

67 the most severe forms of dystroglycanopathy, and causes multiple structural brain and

68 retinal abnormalities due to its indirect role in regulating neuronal migration and axon

69 guidance (Clements et al., 2017; Lindenmaier et al., 2019; Moore et al., 2002; Myshrall 
et al., 2012; Satz et al., 2010; Wright et al., 2012). However, some individuals with

71 milder forms of dystroglycanopathy exhibit cognitive impairments even in the absence of

72 detectable brain malformations, suggesting a possible role for Dystroglycan at later

73 stages of brain development including synaptogenesis (Godfrey et al., 2007; Mercuri et

74 al., 2009). In PyNs, Dystroglycan is highly concentrated on the cell body and proximal

75 dendrites where it is a major postsynaptic component of inhibitory synapses (Fig. 1A;

76 Brunig et al., 2002; Levi et al., 2002; Uezu et al., 2019; Zaccaria et al., 2001). However,

77 because of its importance in early aspects of brain development, the role of

78 Dystroglycan at synapses has remained obscure. Using a mouse genetic approach to selectively delete Dystroglycan from PyNs, a recent study showed that Dystroglycan is

80 required for the proper function of $\mathrm{CCK}+$ interneuron $(\mathrm{CCK}+\mathrm{IN})$ synapses in adult

81 animals, but its specific role in the development of these synapses has not been

82 examined (Fruh et al., 2016).

In this study, we show that postsynaptic Dystroglycan on PyNs is required for the

84 proper development of presynaptic CCK+ INs throughout the forebrain. In mice lacking

85 Dystroglycan in PyNs, CCK+ INs fail to elaborate their axons during the first postnatal week and are largely absent by P10. CCK+ INs were not rescued by genetic deletion of

87 Bax suggesting that CCK+ INs may undergo Bax-independent cell death or fail to

88 differentiate in the absence of Dystroglycan. Some remaining CCK+ INs retarget their

89 axons into the striatum, where Dystroglycan expression is retained, suggesting that

90 Dystroglycan functions to allow CCK+ INs to recognize their synaptic partners.

91 Collectively, these results demonstrate that Dystroglycan is a critical regulator of CCK+

92 IN development. 
94 RESULTS

95 CCK+ interneurons are largely absent in mice lacking Dystroglycan from

96 pyramidal neurons

97 To investigate the role of neuronal Dystroglycan in forebrain development, we

98 used a conditional genetic approach to delete Dystroglycan selectively from pyramidal

99 neurons (PyNs). We crossed Dystroglycan conditional mice (Dag 1Flox/Flox $)$ with Nex ${ }^{\text {Cre }}$

100 driver mice to delete Dystroglycan in all postmitotic excitatory neurons of the forebrain

101 except Cajal-Retzius cells, beginning at E12.5 (Schwab et al., 1998; Goebbels et al.,

102 2006; Belvindrah et al., 2007; Wu et al., 2005). Control (Nex $\left.{ }^{\mathrm{Cre}} ; \mathrm{Dag} 1^{\mathrm{F} /+}\right)$ and conditional

103 knockout mice (Nex $\left.{ }^{\mathrm{Cre}} ; \mathrm{Dag} 1^{\mathrm{F} /}\right)$ are hereafter referred to as Dag $1^{\text {Control }}$ and Dag $1^{\mathrm{cKO}}$

104 mice, respectively (Fig. 1B). We verified the recombination specificity of the Nex ${ }^{\text {Cre }}$ line

105 by crossing it with a reporter mouse that expresses mCherry in the nuclei of Cre-

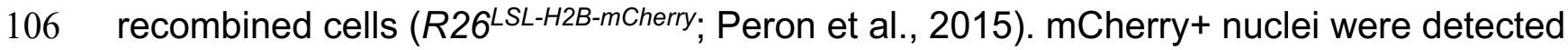

107 in excitatory neurons of the forebrain including the cortex, hippocampus, amygdala, and

108 nucleus of the lateral olfactory tract (nLOT) (Fig. S1A). Importantly, mCherry+ nuclei did

109 not overlap with markers for interneurons ( $\mathrm{CB}_{1} \mathrm{R}, \mathrm{PV}$, Calbindin) or astrocytes (GFAP),

110 confirming the specificity of the $N e x^{\text {Cre }}$ mouse (Fig. S1B, C). In Dag $1^{\text {Control mice, }}$

111 Dystroglycan staining was observed as puncta concentrated primarily on the cell bodies

112 and proximal dendrites of PyNs, as well as blood vessels (Fig. 1C). In Dag $1^{\text {cKO }}$ mice,

113 Dystroglycan staining was absent from PyNs but was still present on blood vessels,

114 confirming the specificity of the conditional knockout. 
Deletion of Dystroglycan from neuroepithelial cells results in disrupted neuronal migration, axon guidance, and dendrite development in the brain, spinal cord and retina

117 (Clements et al., 2017; Lindenmaier et al., 2019; Moore et al., 2002; Myshrall et al.,

118 2012; Satz et al., 2010; Wright et al., 2012). In contrast, deletion of Dystroglycan from

119 PyNs with Nex ${ }^{\text {Cre }}$ did not affect overall brain architecture, consistent with previous

120 results (Satz et al., 2010). Cortical lamination in Dag $1^{c K O}$ mice was normal based on

121 CUX1 immunostaining of layer 2-4 PyNs and labeling of layer 5-6 and hippocampal

122 PyNs with a Thy $1^{\text {GFP-H }}$ transgenic line (Fig. 1D-F). Therefore, neuronal Dystroglycan is 123 not required for PyN migration in the forebrain.

124 Forebrain interneurons (INs) are a remarkably diverse population, with multiple

125 molecularly and morphologically distinct IN subtypes forming synapses onto different

126 subcellular domains of PyNs (Huang et al., 2007; Kepecs and Fishell, 2014; Miyoshi et

127 al., 2010). Since Dystroglycan is localized to inhibitory synapses on the soma and

128 dendrites of PyNs, we examined whether IN development is affected in Dag $1^{c K O}$ mice.

129 We performed immunostaining with a panel of molecular markers that label IN

130 subpopulations in the hippocampus of adult mice (Fig. 2). In Dag $1^{\text {Control mice, }}$

131 parvalbumin (PV) and somatostatin (SOM) positive INs, which label the majority of

132 interneurons that originate from the medial ganglionic eminence (MGE), were abundant

133 throughout the hippocampus. The distribution of $\mathrm{PV}+$ and $\mathrm{SOM}+$ cell bodies and their

134 synaptic targeting patterns appeared the same in Dag $1^{c K O}$ mice, suggesting these

135 populations are unaffected by the loss of Dystroglycan (Fig. 2A, B).

136 We next stained the hippocampus for IN subtypes that originate from the caudal

137 ganglionic eminence (CGE). The distribution and synaptic targeting of Calretinin 
138 interneurons, which target other INs as well as PyN dendrites, appeared normal (Fig.

139 2C; Gulyas et al., 1996; Urban et al., 2002). In contrast, we found a dramatic reduction

140 in cannabinoid receptor-1 $\left(\mathrm{CB}_{1} \mathrm{R}\right)$ staining in the hippocampus, which labels the axon

141 terminals of cholecystokinin (CCK)+ INs (Fig. 2D; Katona et al., 1999; Marsicano and

142 Lutz, 1999; Tsou et al., 1998). $\mathrm{CB}_{1} \mathrm{R}+$ terminals were significantly reduced in all CA

143 subregions (Fig. 2E, F). In both the CA1 and CA3, the magnitude of the reduction

144 varied by layer. $\mathrm{CB}_{1} \mathrm{R}+$ terminals were most strongly reduced $(>95 \%)$ in the stratum

145 pyramidale (SP) where CCK+ INs form basket synapses onto PyN cell bodies, and

146 more moderately reduced in the stratum radiatum (SR) and stratum oriens (SO) where

$147 \mathrm{CCK} / \mathrm{CB}_{1} \mathrm{R}+\mathrm{INs}$ synapse onto PyN dendrites (Fig. 2E, F). In contrast, $\mathrm{CB}_{1} \mathrm{R}+$ terminals

148 were abundant in the dentate gyrus of Dag $1^{\text {CKO }}$ mice (Fig. S2). This is likely because

149 Nex ${ }^{\text {Cre }}$ recombination is restricted to the outer third of granular layer neurons (Fig. S1C;

150 Goebbels et al., 2006).

151 The loss of $\mathrm{CB}_{1} \mathrm{R}$ staining in the hippocampus of Dag $1^{\text {cKO }}$ mice could reflect

152 either downregulation of $\mathrm{CB}_{1} \mathrm{R}$ expression or a loss of $\mathrm{CCK}+\mathrm{INs}$. To distinguish

153 between these possibilities, we examined whether other independent markers of CGE-

154 derived CCK+ INs were similarly reduced. These include NECAB1, a calcium binding

155 protein that specifically labels CCK+ IN cell bodies (Fig. 3A) (Miczan et al., 2021), and

156 VGLUT3, a vesicular glutamate transporter enriched at CCK+ IN synapses (Fig. 3C)

157 (del Pino et al., 2017; Pelkey et al., 2020; Somogyi et al., 2003). Both NECAB1+ cell

158 bodies and VGLUT3+ synaptic terminals were reduced in the hippocampus of Dag $1^{\text {cKO }}$

159 mice (Fig. 3B, D). Based on the loss of all three markers, we conclude that CCK+ INs

160 are largely absent from the hippocampus of $D a g 1^{c K O}$ mice. 
In addition to the hippocampus, Dystroglycan is present in PyNs of the cortex,

163 all receive extensive innervation from CCK+ INs (Herkenham et al., 1990, 1991; Katona

164 et al., 2001). Therefore, we assessed whether deletion of Dystroglycan from PyNs

165 affects CCK+ INs and their terminals in these forebrain regions. We first performed

166 immunostaining for $\mathrm{CB}_{1} \mathrm{R}$ on sagittal sections from $D a g 1^{\text {Control }}$ and $D a g 1^{c K O}$ mice. $\mathrm{CB}_{1} \mathrm{R}$

167 terminals were largely absent throughout the entire forebrain of Dag $1^{\text {cKO }}$ mice (Fig. 4A,

168 B). Next, we stained P30 Dag $1^{\text {Control }}$ and Dag $1^{c K O}$ mice for NECAB1 and CB ${ }_{1}$ to label

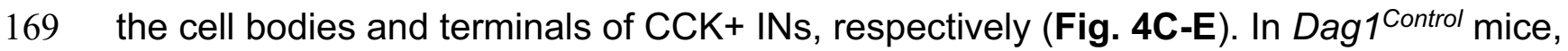

170 NECAB1+ cell bodies were numerous and $\mathrm{CB}_{1} \mathrm{R}$ innervation was extensive in the

171 cortex, amygdala, and nLOT. In contrast, NECAB1+ cell bodies were dramatically

172 reduced, and $\mathrm{CB}_{1} \mathrm{R}$ staining was almost completely absent in all regions of Dag1cKO

173 mice (Fig. 4C-E). In each region, a few NECAB1+ cell bodies remained in Dag $1^{c K O}$

174 mice, and these co-localized with $\mathrm{CB}_{1} \mathrm{R}$. Therefore, Dystroglycan expressed in PyNs is

175 required broadly in the developing forebrain for the proper integration of CCK+ INs.

\section{Postnatal development of CCK+ interneurons is impaired in the forebrains of}

178 Dag1 ${ }^{\text {cKo }}$ mice

179 Our results showing that deletion of Dystroglycan from PyNs leads to a reduction

180 in CCK+ IN innervation is consistent with previous work (Fruh et al., 2016). However,

181 the temporal onset of this phenotype has not been determined. During embryonic

182 development, CCK+ INs generated in the caudal ganglionic eminence (CGE) begin

183 populating the hippocampus around E14.5 (Calvigioni et al., 2017; Tricoire et al., 2011) 
184 (Fig. 5A). At postnatal ages, CCK+ INs settle into their final positions within the

185 hippocampus and initially extend axons throughout the hippocampal layers before

186 refining their projections to form characteristic basket synapses onto PyN somas (Fig.

187 5B, D) (Morozov et al., 2003a; 2003b; 2009). We first examined the development of

$188 \mathrm{CB}_{1} \mathrm{R}+$ terminals in Dag1 ${ }^{\text {Control }}$ mice during the first two postnatal weeks (P3-P15), as

$189 \mathrm{CB}_{1} \mathrm{R}$ staining is largely absent from CCK+ INs before birth (Berghuis et al., 2007;

190 Eggan et al., 2010; Mulder et al., 2008; Vitalis et al., 2008). At early postnatal ages (P3-

$191 \mathrm{P} 5)$, the majority of $\mathrm{CB}_{1} \mathrm{R}+$ terminals were observed in the stratum radiatum (SR) layer

192 of the hippocampus, where immature PyN dendrites are located (Fig. 5B, D). Between

193 P5 and P10, CB 1 R+ terminals increased in the stratum pyramidale (SP) where PyN cell

194 bodies are located. From P15 through adulthood (15 months), CB 1 R+ terminals became 195 progressively concentrated in the SP.

196 Next, we examined $\mathrm{CB}_{1} \mathrm{R}+$ terminal development in Dag $1^{\text {cKO }}$ mice. At P3, the

197 earliest age we were able to conclusively identify $\mathrm{CCK}+\mathrm{INs}, \mathrm{CB}{ }_{1} \mathrm{R}+$ staining was

198 already reduced in the hippocampus of $D a g 1^{\text {cKO }}$ mice. This reduction persisted

199 throughout the period of postnatal development and into adulthood, as late as 15

200 months (Fig. 4C, E, F). To further confirm this finding, we stained the hippocampus for

201 VGLUT3, an independent synaptic marker for CCK+ IN terminals that is upregulated

202 during early postnatal ages (Fig. S3A). In Dag1 ${ }^{\text {Control }}$ mice, VGLUT3+ terminals

203 increased in the hippocampus during the first two postnatal weeks, and showed a

204 similar pattern of innervation as $\mathrm{CB}_{1} \mathrm{R}+$ staining (Fig. S3B). In contrast, VGLUT3+

205 terminals were reduced at all ages examined in Dag $1^{c K O}$ mice (Fig. S3B). PV staining, 
206 which increases between P10 and P15 (del Rio et al., 1994), was unaltered in Dag1cko

207 mice compared with controls (Fig. S3C).

208 We next determined whether the reduction of CCK+ INs in the cortex, amygdala,

209 and nLOT followed the same developmental time course as the hippocampus. In

210 Dag1 $1^{\text {Control mice, }} \mathrm{CB}_{1} \mathrm{R}+$ terminals gradually increased in density in all regions between

211 P3 and P15, and remained stable beyond this age into adulthood (15 months) (Fig. 6).

212 In contrast, $\mathrm{CB}_{1} \mathrm{R}+$ terminals in $D a g 1^{c K O}$ mice failed to elaborate during the first two

213 postnatal weeks, and remained sparse in adult animals. Collectively, these results

214 demonstrate that Dystroglycan in PyNs is critical during the first two postnatal weeks for

215 the development and integration of CCK+ INs throughout the forebrain.

217 Post-developmental maintenance of CCK+ interneurons does not require

\section{Dystroglycan}

Inhibitory synaptogenesis increases between P5-P15, and is largely complete by

P30 (Favuzzi et al., 2019; Pelkey et al., 2020; Tai et al., 2019). Therefore, we wanted to

221 assess whether deletion of Dystroglycan after inhibitory synapse formation impairs the

222 maintenance of CCK+ INs. To achieve temporal control of Dystroglycan deletion from

223 PyNs, we generated mice expressing tamoxifen-inducible Cre recombinase under the

224 control of an excitatory neuron-specific promoter Camk2a, (Calcium/calmodulin-

225 dependent protein kinase II alpha; Madisen et al., 2010). Control

226 (Camk2a $\left.{ }^{\text {CreERT2;DG }}{ }^{F /+} ; A i 9\right)$ or inducible-cKO (Camk2aCreERT2;DG ${ }^{F /-; A i 9) ~ m i c e ~ w e r e ~}$

227 administered tamoxifen at P23 via oral gavage, which induced recombination in the

228 majority of PyNs in the hippocampus (Fig. 7A, B). We then analyzed $\mathrm{CB}_{1} \mathrm{R}+$ innervation 
six weeks later at P65. No differences were found between the Dag1 inducible-cKO and

230 controls, suggesting that Dystroglycan is not required for the post-developmental

231 maintenance of CCK+ INs (Fig. 7C, D).

232

233 Blocking Bax-dependent cell death does not rescue CCK+ interneurons in

234 Dag1cko mice

The number of PyNs and INs in the forebrain is tightly regulated during early

236 postnatal development, with excess or inappropriately connected neurons pruned by

237 Bax-dependent apoptosis (Carriere et al., 2020; Mancia Leon et al., 2020; Priya et al.,

238 2018; Southwell et al., 2012). PyN apoptosis is largely complete by P5, followed by IN

239 apoptosis which peaks at P7-P9. We hypothesized that in the absence of PyN

240 Dystroglycan, CCK+ INs are unable to recognize their postsynaptic targets and are

241 therefore eliminated by apoptosis. We tested this hypothesis by generating Dag $1^{\text {Ctrl }}$ and

242 Dag $1^{\text {cKO }}$ mice that lack either one $\left(\right.$ Dag $1^{C t r l} ; B a x^{C t r l}$ and Dag $\left.1^{\text {cKO;}} ; B a x^{C t r l}\right)$ or both copies

243 of $\operatorname{Bax}\left(\operatorname{Dag} 1^{\mathrm{Ctrl}} ; \mathrm{Bax}^{\mathrm{KO}}\right.$ and $\left.\mathrm{Dag}{ }^{\mathrm{cKO}} ; \mathrm{Bax}^{\mathrm{KO}}\right)$ to block apoptosis (Fig. 8A). Deletion of Bax

244 from control mice $\left(\operatorname{Dag}{ }^{\mathrm{Ctrl}} ; \mathrm{Bax}^{\mathrm{KO}}\right)$ did not alter $\mathrm{CB}_{1} \mathrm{R}+$ innervation in the $\mathrm{CA} 1$ subregion

245 of the hippocampus (Fig. 8B-C, F). In line with our previous results, Dag ${ }^{c K O ; B a x}{ }^{C t r l}$

246 mice lacking one copy of Bax had a similar reduction in $\mathrm{CB}_{1} \mathrm{R}+$ terminals as $D a g 1^{\text {cKO }}$

247 mice (Fig. 8D, F). Surprisingly, we found that complete deletion of Bax in Dag $1^{\text {cKO }}$ mice

248 (Dag $\left.{ }^{\text {cKO }} ; \mathrm{Bax}^{\mathrm{KO}}\right)$ was not sufficient to rescue $\mathrm{CB}_{1} \mathrm{R}+$ innervation (Fig. 8E, F). Staining

249 for an additional CCK+ IN synapse marker (VGLUT3) further confirmed this result (Fig.

250 S4). Finally, we examined whether deletion of Bax could rescue $C_{1} R+$ innervation in

251 the cortex, amygdala, and the nucleus of the lateral olfactory tract (nLOT) of Dag $1^{\text {cKO }}$ 
252 mice (Fig. S5). In all regions examined, $\mathrm{CB}_{1} \mathrm{R}+$ terminals were reduced in mice lacking

253 Dystroglycan (Dag $\left.{ }^{c K O} ; B a x^{C t r l}\right)$. Similar to our observations in the hippocampus, deleting

254 both copies of $\operatorname{Bax}\left(\operatorname{Dag} 1^{c K O} ; \mathrm{Bax}^{\mathrm{KO}}\right)$ was not sufficient to rescue $\mathrm{CB}_{1} \mathrm{R}+$ innervation in

255 the cortex, amygdala, or nLOT (Fig. S5). Collectively, these results suggest that loss of

$256 \mathrm{CB}_{1} \mathrm{R}+$ innervation in the absence of PyN Dystroglycan is not due to $\mathrm{CCK}+\mathrm{INs}$

257 undergoing Bax-dependent apoptosis.

CCK+ interneurons inappropriately innervate the striatum of Dag ${ }^{c K O}$ mice

260 During embryonic development, CCK+ INs are produced in and migrate through

261 the caudal ganglionic eminence (CGE), one of two ventral forebrain regions that

262 ultimately develop into the striatum. Expression of Dystroglycan in striatal neurons is

263 retained in Dag ${ }^{c K O}$ mice, as they are not targeted by $N e x^{C r e}$ (Fig. 4A-B; Fruh et al.,

264 2016; Goebbels et al., 2006). We therefore examined $C_{1} B_{1}$ innervation of the striatum

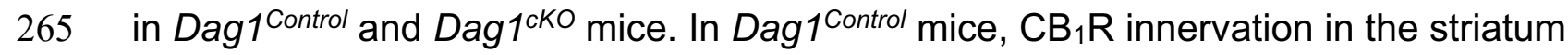

266 was present, but sparse compared with neighboring regions of the cortex (Fig. 9A)

267 (Davis et al., 2018; Van Waes, et al., 2012). In contrast, CB 1 R innervation in the

268 striatum of $D a g 1^{\text {cKO }}$ mice was noticeably increased (Fig. 9C, I). The lateral regions of

269 the striatum closest to the cortex exhibited dense $C_{B} B_{1} R$ innervation, which decreased

270 towards the medial striatum. Global deletion of Bax from Dag $1^{\text {Control }}$ or Dag $1^{\text {cKO }}$ mice did

271 not alter the pattern of $\mathrm{CB}_{1} \mathrm{R}$ innervation in the striatum (Fig. 9B, D).

272 Examination of the developmental timecourse of $\mathrm{CB}_{1} \mathrm{R}+$ innervation in the

273 striatum revealed sparse $\mathrm{CB}_{1} \mathrm{R}+$ terminals at $\mathrm{P} 10$ in both Dag1 ${ }^{\text {Control }}$ and Dag ${ }^{\text {ckO }}$ mice

274 (Fig. 9E), which increased in Dag $1^{c K O}$ mice compared with controls between P15 and 
275 P30 (Fig. 9F-G). This coincides with the period of $\mathrm{CB}_{1} \mathrm{R}+$ innervation of forebrain

276 targets in Dag1 ${ }^{\text {Control }}$ mice. Occasionally, $\mathrm{CB}_{1} \mathrm{R}+$ cell bodies could be seen in the cortex

277 near the striatal boundary, with their axon terminals projecting into the striatum (Fig.

278 9H). These results suggest that some CCK+ INs in the cortex of Dag $1^{\text {cKO }}$ mice may

279 redirect their axons into the neighboring regions of the striatum that retain Dystroglycan.

281 DISCUSSION

Dystroglycan plays a critical role in maintaining the integrity of the neuroepithelial scaffold during early stages of brain development, which has made it difficult to assess

284 its function within neurons at subsequent stages. In the current study, we show that

285 Dystroglycan in pyramidal neurons regulates the development of a subset of their pre-

286 synaptic partners. When Dystroglycan is selectively deleted from PyNs, CCK+ INs

287 throughout the entire forebrain fail to properly integrate, and largely disappear during

288 the first postnatal week. Surprisingly, we found that deletion of Bax did not rescue CCK+

289 INs in Dag1 $1^{\text {KKO }}$ mice, suggesting their disappearance is not due to apoptotic cell death.

290 The few remaining CCK+ INs redirect their axons into neighboring regions of the brain

291 in which Dystroglycan is still present, suggesting that Dystroglycan functions as a part of 292 a synaptic partner recognition complex.

\section{What stage of CCK+ interneuron development requires Dystroglycan?}


298 et al., 2019). Recently, it was found that Dystroglycan is required for the function of

299 CCK+ inhibitory basket synapses, but not PV+ basket synapses onto the same PyNs

300 (Fruh et al., 2016). This finding is significant, because very little is known about the

301 molecules and mechanisms involved in orchestrating the formation of specific subtypes

302 of inhibitory synapses (Krueger-Burg et al., 2017). However, since the earliest timepoint

303 examined in this previous study was P21, it was unclear what stage of synapse

304 development requires Dystroglycan.

305 During neural circuit development, neurons must first migrate and direct their

306 axons to their appropriate targets, then recognize the appropriate synaptic partners from

307 a myriad of potential choices, then finally form functional synapses (Sanes and

308 Zipursky, 2020). Our data suggest that Dystroglycan is required for the least understood

309 of these processes: synaptic partner recognition. This is supported by the observation

310 that CCK+ INs are present at the earliest stages they can be conclusively identified in

311 the forebrain of $D a g 1^{c K O}$ mice $(\mathrm{P} 3)$, but then fail to elaborate their axons and integrate

312 into these circuits during the first postnatal week (Figs. 5, S3, 6). Interestingly, the few

313 remaining CCK+ INs appear to project their axons into regions that continue to express

314 Dystroglycan in Dag1cKO mice (Fig. 5, 9). Taken together, this data suggests that CCK+

315 INs in Dag $1^{\text {cKO }}$ mice fail to recognize their normal postsynaptic PyN targets in the

316 hippocampus and cortex during early postnatal development, and instead re-route to

317 neighboring Dag1+ neurons, discussed further below.

318 The process of synaptic partner recognition in mammals has been difficult to

319 study due to our inability to precisely identify and genetically manipulate the specific

320 neuronal populations during development. Determining whether loss of Dystroglycan 
321 impairs CCK+ IN development before birth is technically challenging due to the lack of

322 immunohistochemical and genetic tools for detecting CCK+ INs prenatally (Calvigioni et

323 al., 2017). The cannabinoid receptor-1 (Cnr1) and cholecystokinin (Cck) genes are both

324 expressed in PyNs at prenatal timepoints, limiting their usefulness for detecting CCK+

325 INs. Transcription factors such as Prox1 are also of limited usefulness due to its broad

326 expression in multiple CGE-derived IN subtypes (Miyoshi et al., 2015). VGLUT3, which

327 labels a subset of CCK+ INs, does not increase in expression until the first postnatal

328 week (Pelkey et al., 2020). Other IN subtypes exhibit delayed expression of selective

329 molecular markers as well. For instance, MGE-derived Parvalbumin INs do not begin to

330 express Parvalbumin until P10, well after the period of initial synaptic partner

331 recognition (Carlen et al., 2012; del Rio et al., 1994).

\section{What happens to CCK+ interneurons in the absence of Dystroglycan?}

334 Our results show that deletion of Dystroglycan from PyNs resulted in a loss of all

335 of the markers we used to identify CCK+ INs in the forebrain (Figs. 2, 3, 4). What

336 happens to these neurons in the absence of PyN Dystroglycan? One possibility that we

337 examined is that CCK+ INs undergo apoptosis. During the first two weeks of

338 development (P5-P10), a significant number of excitatory and inhibitory neurons are

339 pruned by Bax-dependent apoptotic cell death (Carriere et al., 2020; Mancia Leon et al.,

340 2020; Priya et al., 2018; Southwell et al., 2012). This ensures the proper number of

341 neurons and removes neurons that fail to integrate into the developing circuit. Whereas

342 Bax-dependent developmental cell death has been described for most MGE and CGE-

343 derived interneuron subtypes, whether CCK+ INs normally undergo the same process 
344 has not been directly examined (Priya et al., 2018; Southwell et al., 2012). We tested

345 whether the loss of CCK+ INs in Dag1 ${ }^{\text {cKO }}$ mice could reflect premature or amplified

346 developmental apoptosis, which peaks around P9 for other IN subtypes. However,

347 constitutive deletion of Bax, which is sufficient to block developmental apoptosis in other

348 neuronal populations, did not rescue CCK+ INs (Figs. 8, S4, S5). This suggests that

349 canonical apoptosis is not responsible for the loss of CCK+ INs in Dag ${ }^{c K O}$ mice. It is

350 possible that $\mathrm{CCK}+$ INs are eliminated in a Bax-independent manner, similar to some

351 populations of Cajal-Retzius cells in the cortex and astrocytes in the developing retina

352 (Ledonne et al., 2016; Punal et al., 2019).

$353 \mathrm{CCK}+$ INs comprise a molecularly and morphologically diverse group of cells that

354 include both cell body targeting (perisomatic) and multiple dendrite targeting subtypes

355 (Cope et al., 2002; Pelkey et al., 2020; Szabo et al., 2014). In the hippocampus, CCK+

356 INs frequently express one of two non-overlapping markers, VGLUT3 ( 45\%) and VIP

357 ( 16\%) (del Pino et al., 2017). In Dag $1^{c K O}$ mice, all synaptic and cell body markers

358 selective for $\mathrm{CCK}+$ INs $\left(\mathrm{CB}_{1} \mathrm{R}, \mathrm{VGLUT3}, \mathrm{NECAB} 1\right)$ that we examined were reduced at

359 the onset of their expression. While it is formally possible that Dystroglycan in PyNs is

360 required for CCK+ INs to fully differentiate into their mature, molecularly defined

361 subtype, we consider this unlikely. In this situation, Dystroglycan present on PyNs would

362 be required to transmit a retrograde signal to $\mathrm{CCK}+\mathrm{INs}$ to direct their differentiation. We

363 are unaware of any cell adhesion molecules that function in this manner. Rather, fate

364 switching or failure to fully differentiate is usually observed upon cell-autonomous loss

365 of specific transcription factors (Guillemot, 2007). 
Our data also indicate that Dystroglycan is not required to maintain CCK+ INs after the period of synapse formation (Fig. 7). This is in contrast to a previous study that showed a gradual reduction in the number of Vglut3+ puncta when Dag1 was deleted in adult mice using AAV-Cre (Fruh et al., 2016). Aside from the different approaches used for adult deletion, this difference may arise from the level of analysis: in our study, we

371 saw no difference in the cellular organization of CCK+ INs following adult deletion,

372 whereas the previous study was focused specifically on presynaptic puncta. It is

373 possible that in our inducible-cKO (Camk2a ${ }^{C r e E R T 2 ; D G F / ; A i 9) ~ m i c e, ~ s y n a p t i c ~ i n p u t s ~ f r o m ~}$

$374 \mathrm{CCK}+$ INs are reduced without altering the survival of these neurons.

Although CCK+ INs and their terminals were dramatically reduced throughout the

376 brains of Dag $1^{\text {cKO }}$ mice, some CCK+ IN terminals were still present, particularly along

377 the cortico-striatal boundary and in the upper dendritic layers of the cortex (layer 1) and

378 hippocampus. Importantly, striatal neurons and Cajal-Retzius cells, which are located in superficial cortical layers during postnatal development, are not targeted by Nex ${ }^{\mathrm{Cre}}$ (del

380 Rio et al., 1995). This suggests that in the absence of Dystroglycan on their normal 381 postsynaptic targets (PyNs), CCK+ INs may direct their axons to secondary synaptic

382 targets that retain Dystroglycan expression.

383 A number of studies have indicated that synaptic partner recognition and

384 targeting may be "stringent" or "flexible", depending on the cell type involved. In the 385 developing retina, On-alpha retinal ganglion cells will re-wire to increase inputs from 386 neighboring bipolar cell types when their normal presynaptic inputs (Type 6 bipolar 387 cells) are genetically ablated (Tien et al., 2017). Studies in Drosophila have shown that 388 synaptic cell adhesion molecules such as DIP/Drps act to bias synapse formation 
389 towards primary synaptic targets (Xu et al., 2019). In the absence of these interactions,

390 neurons can form ectopic synapses with alternative partners. In contrast, preGABA INs

391 in the developing spinal cord retract their processes when their primary targets

392 (proprioceptor axons) are not present, rather than forming synapses onto secondary

393 targets (Betley et al., 2009). Despite retracting their axons, preGABA INs do not

394 undergo cell death, suggesting that loss of neurons is not a necessary consequence of

395 losing synaptic partners. In Dag $1^{\text {cKO }}$ mice, CCK+ INs may stringently require

396 Dystroglycan for their ability to recognize their primary synaptic targets and die in a Bax-

397 independent manner in its absence. The observation that some CCK+ INs near the

398 cortico-striatal boundary survive and innervate the striatum suggests that they may

399 exhibit some degree of flexibility to make contacts onto secondary targets. Determining

400 whether the remaining CCK+ INs in Dag $1^{C K O}$ mice exhibit normal morphological and

401 physiological properties will require fate mapping these neurons, which is difficult with

402 currently available genetic tools.

404 Why are CCK+ interneurons selectively affected in Dag $1^{\text {cKo }}$ mice?

405 CCK+ INs appear to be the only interneuron subtype affected by deletion of

406 Dystroglycan from PyNs. Compared to other IN populations, CCK+ INs express high

407 levels of $\mathrm{CB}_{1} \mathrm{Rs}$, which can play important roles in neuronal proliferation, migration, and

408 axon outgrowth (Gaffuri et al., 2012). In utero exposure to exogenous cannabinoids

409 results in a specific loss of CCK+ INs through unknown mechanisms (Vargish et al.,

410 2017). However, conditional deletion of the cannabinoid receptor-1 gene Cnr1 from

$411 \mathrm{CCK}+$ INs does not affect interneuron migration or neurochemical specification, but 
412 rather increases the number of perisomatic VGLUT3+ inhibitory synapses on cortical

413 PyNs (Berghuis et al., 2007). In addition, $\mathrm{CB}_{1} \mathrm{R}$ signaling is not necessary for the

414 survival of CCK+ INs (Albayram et al., 2016). Therefore, it is unlikely that alterations in

$415 \mathrm{CB}_{1} \mathrm{R}$ activity underlie the selective loss of $\mathrm{CCK}+\mathrm{INs}$ in Dag ${ }^{c K O}$ mice.

416 One possible explanation for this selective loss is that Dystroglycan interacts with

417 specific molecules on presynaptic CCK+ INs compared with other IN subtypes.

418 Dystroglycan is highly glycosylated, and unique matriglycan moieties present on its

419 extracellular domain bind to proteins containing Laminin G (LG) domains (Yoshida-

420 Moriguchi and Campbell, 2015). Proteins that bind Dystroglycan through their LG

421 domains include extracellular matrix proteins (Agrin, Laminins, Perlecan), axon

422 guidance molecules (Slits, Celsr3), as well as synaptic proteins (Neurexin, Pikachurin)

423 (Campanelli et al., 1994; Gee et al., 1994; Ibraghimov-Beskrovnaya et al., 1992; Peng

424 et al., 1998; Sato et al., 2008; Sugita et al., 2001; Wright et al., 2012; Lindenmaier et al.,

425 2019). Several other putative synaptic proteins also contain LG domains (ie: Cntnap1-

426 6), although their binding to Dystroglycan has not been examined.

427 Biochemical experiments have identified $\alpha-D G$ as a major interaction partner of

$428 \alpha$ - and $\beta$-neurexins in whole brain lysates, and these interactions are dependent upon

429 the lack of splice inserts in LNS2 and LNS6 of neurexin (Sugita et al., 2001; Boucard et

430 al., 2005; Reissner et al., 2014; Fucillo, et al., 2015). Conditional deletion of all three

431 Neurexins from interneurons revealed distinct outcomes depending on the IN population

432 examined (Chen et al., 2017). Deletion of all Neurexin isoforms from PV+ INs results in

433 a significant decrease in the number of PV+ synapses in the cortex, whereas it does not

434 affect inhibitory synapse numbers when deleted from SST+ INs. While PV+ IN numbers 
435 were not affected by conditional deletion of Neurexins, this could reflect the timing of

436 deletion, which is unlikely to occur before three weeks of age based on the onset of Cre

437 expression (Carlen et al., 2012; del Rio et al., 1994). Nrxn1 $\alpha$ and Neurexin $3 \alpha / \beta$ are

438 expressed at significantly higher levels in CCK+ INs than in PV+ INs, and CCK+ INs

439 predominantly express Neurexin isoforms lacking splice inserts in LNS6 (Fucillo, et al.,

440 2015). Therefore, CCK+ INs may show a larger degree of Nrxn:Dystroglycan interaction

441 than other IN subtypes. Mice harboring a mutation in Dystroglycan that exhibits reduced

442 glycosylation, and thus Neurexin binding capacity (Dag $\left.1^{T 190 M}\right)$, showed no impairments

443 in CCK+ IN terminal development (Fruh et al., 2016; Hara et al., 2011). However, these

444 mice do not display the cortical migration phenotypes associated with a complete loss of

445 Dystroglycan, suggesting that Dystroglycan retains some residual function, which may

446 be sufficient for CCK+ IN terminal development. Whether Neurexins are required cell

447 autonomously in $\mathrm{CCK}+$ INs for their development has not been directly tested, in part

448 due to a lack of genetic tools.

450 Limitations in studying CCK+ interneuron development

451 Our understanding of CCK+ IN development and function has lagged behind other

452 interneuron subtypes (PV, SOM, VIP, etc) due in part to the lack of viral and mouse

453 genetic tools available for selectively labeling and manipulating CCK+ INs. All major

454 markers of CCK+ INs (CCK, CB1R, and VGLUT3) are also expressed at lower levels in

455 PyNs, limiting the usefulness of single promoter/recombinase approaches for targeting

456 CCK+ INs (Dimidschstein et al., 2016; Tasic et al., 2016; Zeisel et al., 2015). Specific

457 targeting of CCK+ INs therefore requires dual recombinase-based intersectional 
458 approaches, including CCK-Cre;Dlx5/6-Flp double transgenic mice (Nguyen et al.,

459 2020; Taniguchi et al., 2011; Rovira-Esteban et al., 2019; Whissell et al., 2015; Whissell

460 et al., 2019), dual CCK-dsRed;GAD67-GFP reporter mice (Calvigioni et al., 2017), or

461 VGLUT3 ${ }^{\text {Cre }}$ mice which label approximately half of CCK+ INs (Fasano et al., 2017;

462 Pelkey et al., 2020). Other reporter lines (5HT3AR $\left.{ }^{E G F P}\right)$ target the entire CGE-derived

463 interneuron population, of which CCK+ INs only comprise $\sim 10 \%$ (Chittajallu et al., 2013;

464 Lee et al., 2010). A recently developed Sncg ${ }^{F l p O}$ mouse line appears to provide selective

465 genetic access CCK+ basket cells by taking advantage of the fact that Sncg is

466 specifically expressed in CCK+ INs (Dudok et al., 2021). However, it is not clear when

467 the onset of recombination occurs in this line, and whether it will be useful for studying

468 the early development of CCK+ INs. Indeed, many of the genes used for targeting IN

469 subtypes are not significantly expressed until after the first postnatal week in mice,

470 when much of the process of synaptic partner recognition and initial synapse formation

471 has already occurred (Fig. S3; Carlen et al., 2012; del Rio et al., 1994; Pelkey et al.,

472 2020).

\section{CONCLUSION}

In this study, we identified a critical role for excitatory neuron Dystroglycan in

476 regulating the development of forebrain $\mathrm{CCK}+$ interneurons during the first postnatal

477 week. Given the emerging role for CCK+ INs and cannabinoid signaling in controlling

478 neural circuit activity, Dag $1^{c K O}$ mice may be useful for studying the consequences of

479 losing a major IN population. 


\section{MATERIALS AND METHODS}

\section{Animal husbandry}

483 All animals were housed and cared for by the Department of Comparative Medicine

484 (DCM) at Oregon Health and Science University (OHSU), an AAALAC-accredited

485 institution. Animal procedures were approved by OHSU Institutional Animal Care and

486 Use Committee (Protocol \# IS00000539) and adhered to the NIH Guide for the care and

487 use of laboratory animals. Animals older than postnatal day 6 (P6) were euthanized by

488 administration of $\mathrm{CO}_{2}$, animals $<\mathrm{P} 6$ were euthanized by rapid decapitation. Animal

489 facilities are regulated for temperature and humidity and maintained on a 12 hour light-

490 dark cycle and animals were provided food and water ad libitum.

\section{Mouse strains and genotyping}

493 The day of birth was designated postnatal day 0 (P0). Ages of mice used for each

494 analysis are indicated in the figure and figure legends. Mice were maintained on a

495 C57BL/6 background and have been previously described or obtained from JAX (Table

496 1): Dystroglycan conditional mice (Dag1Flox) (Cohn et al., 2002; Moore et al., 2010),

$497 N^{\text {Cre }}$ (Schwab et al., 1998; Goebbels et al., 2006), VGLUT3 ${ }^{\text {Cre }}$ (Grimes et al., 2011),

$498 \mathrm{Bax}^{-/-}$(Knudson et al., 1995; White et al., 1998), Camk2aCreERT2 (Madisen et al., 2010),

499 Aig ${ }^{\text {LSL-tdTomato }}$ (Madisen et al., 2010), and R26 $6^{\text {LSL-H2B-mCherry }}$ (Peron et al., 2015). Genomic

500 DNA extracted from tissue samples (Quanta BioSciences) was used to genotype

501 animals. The presence of the Cre allele in Nex ${ }^{\text {Cre }}$ mice and Camk2aCreERT2 mice was

502 detected using generic Cre primers (JAX).

503 Table 1. Mouse strains

\begin{tabular}{|l|l|l|l|}
\hline Common name & Strain name & Reference & Stock \# \\
\hline
\end{tabular}


504

505

506

507

508 tamoxifen.

\section{Perfusions and tissue preparation}

511 Brains from mice younger than P15 were dissected and fixed in 4\% paraformaldehyde

512 (PFA) in phosphate buffered saline (PBS) overnight for $18-24 \mathrm{hrs}$ at $4^{\circ} \mathrm{C}$. Mice P15 and

513 older were deeply anesthetized using CO2 and transcardially perfused with ice cold

$514 \quad 0.1 \mathrm{M}$ PBS for two minutes to clear blood from the brain, followed by $15 \mathrm{~mL}$ of ice cold

515 4\% PFA in PBS. After perfusion, brains were dissected and post-fixed in 4\% PFA for

516 two hours. Brains were rinsed with PBS, embedded in 4\% low-melt agarose (Fisher:

517 Cat\# 16520100), and $50 \mu \mathrm{m}$ sections were cut on a vibratome (VT1200S, Leica

518 Microsystems Inc., Buffalo Grove, IL).

\section{Immunohistochemistry and antibodies}

521 Single and multiple immunofluorescence detection of antigens was performed as

522 follows: Free-floating vibratome sections $(50 \mu \mathrm{m})$ were briefly rinsed with PBS, then 
523 blocked for $1 \mathrm{hr}$ in PBS containing $0.2 \%$ Triton-X (PBST) plus 10\% normal donkey

524 serum. Sections were incubated with primary antibodies (Table 2) diluted in PBST at

$5254^{\circ} \mathrm{C}$ overnight (18-24 hrs) or for 3 days for Dystroglycan staining. The following day,

526 sections were rinsed briefly with PBS, then washed with PBST three times for 20 min

527 each. Sections were then incubated with a cocktail of secondary antibodies (1:1000,

528 Alexa Fluor 488, 546, 647; Fisher) in PBST for 90 min at room temperature. Sections

529 were washed with PBS three times for 20 min each and counterstained with Hoechst

53033342 (Life Technologies, Cat\# H3570) for 10 min to visualize nuclei. Finally, sections

531 were mounted on slides using Fluoromount-G (Fisher; SouthernBiotech) and sealed

532 using nail polish.

533

Table 2. Primary antibodies used for immunohistochemistry

\begin{tabular}{|c|c|c|c|c|c|}
\hline Target & Host & Dilution & Source & Catalog \# & RRID \\
\hline $\begin{array}{l}\text { a-Dystroglycan } \\
\text { (IIH6C4) }\end{array}$ & Mouse & $1: 200$ & Millipore & $05-593$ & AB_309828 \\
\hline Calbindin & Rabbit & $1: 4000$ & Swant & СВ38 & AB_10000340 \\
\hline Calretinin & Rabbit & $1: 4000$ & Swant & CG1 & $A B_{-}-2619710$ \\
\hline CB1R & $\begin{array}{l}\text { Guinea } \\
\text { pig }\end{array}$ & $1: 2000$ & Synaptic Systems & 258-104 & AB_2661870 \\
\hline Cux1 & Rabbit & $1: 250$ & Santa Cruz Biotech & sc-13024 & AB_2261231 \\
\hline GFAP & Mouse & $1: 1000$ & Millipore & MAB360 & AB_2109815 \\
\hline NECAB1 & Rabbit & $1: 2000$ & Sigma & HPA023629 & $A B_{-}^{-} 1848014$ \\
\hline Parvalbumin & Goat & $1: 2000$ & Swant & PVG-213 & AB_2650496 \\
\hline Somatostatin & Rabbit & $1: 2000$ & Peninsula Labs & $\mathrm{T}-4103$ & AB_518614 \\
\hline tdTomato & Goat & $1: 1000$ & Biorbyt & orb182397 & AB_2687917 \\
\hline VGlut3 & Rabbit & $1: 2000$ & Synaptic Systems & $135-203$ & AB_887886 \\
\hline
\end{tabular}

536 Microscopy

537 Imaging was performed on a Zeiss Axio Imager M2 fluorescence upright microscope

538 equipped with an Apotome.2 module for structured illumination microscopy. The

539 microscope uses a metal halide light source (HXP 200 C), Axiocam 506 mono camera,

540 and 10X/0.3 NA EC Plan-Neofluar, 20X/0.8 NA Plan-Apochromat objectives. Z-stack 
541 images were acquired and processed as maximum projection images using Zeiss Zen

542 Imaging software, and analyzed offline in ImageJ/FIJI (Schindelin et al., 2012). Images

543 used for quantification between genotypes were acquired using the same exposure

544 times. Brightness and contrast were adjusted in FIJI to improve visibility of images for

545 publication. Figures were composed in Adobe Illustrator CS6 (Adobe Systems).

Quantification

548 Quantification of $\mathrm{CB}_{1} \mathrm{R}$ terminals in the hippocampus (CA1, CA3, Dentate gyrus) and 549 striatum was performed on $5 \mu \mathrm{m}$ z-stacks acquired using a 20X objective. Six to twelve 550 sections per animal (technical replicates) from at least three animals per genotype 551 (biological replicates) were used for analysis, except where noted in the text and figure 552 legends. Sections were taken from equivalent rostro-caudal positions including the 553 dorsal hippocampus (Bregma between -1.48 to $-1.94 \mathrm{~mm}$ ) using coordinates from the 554 mouse brain atlas (Franklin and Paxinos, 1997). All images used for quantification were 555 processed identically. Briefly, background subtraction (Rolling ball radius $=50$ ) and 556 mean filtering (Smooth function in FIJI) were applied to each image to enhance the 557 detection of $\mathrm{CB}_{1} \mathrm{R}$ terminals by thresholding. To measure $\mathrm{CB}_{1} \mathrm{R}$ signal in specific 558 regions of interest (ROIs), a threshold was manually set and applied equally across 559 images to detect only $\mathrm{CB}_{1} \mathrm{R}$ signal. Separate regions of interest (ROIs) were used to 560 quantify $\mathrm{CB}_{1} \mathrm{R}$ pixels in $\mathrm{CA} 1$ and $\mathrm{CA} 3$ layers: stratum oriens (SO), stratum pyramidale 561 (SP) and stratum radiatum (SR). Three separate ROls were used to analyze Dentate 562 gyrus layers: Outer molecular layer (OML), Inner molecular layer (IML), and Granule cell 563 layer (GCL). Hoechst signal in the SP (CA regions) and GCL (Dentate regions) were 
564 used to align the ROls consistently for each image. Raw integrated density values from

565 each ROI were averaged across all images for each animal and normalized to the mean

566 intensity of the control group (set to $100 \%$ for each ROI).

\section{Experimental Design and Statistical Analysis}

569 All phenotypic analyses were conducted using tissue collected from at least three mice 570 per genotype from at least two independent litters unless otherwise noted. The number

571 of mice used for each analysis ("n") are indicated in the figures and figure legends. No

572 specific power analyses were performed, but sample sizes were similar to our previous

573 work and other published literature (Wright et al., 2012; Clements et al., 2017;

574 Lindenmaier et al., 2019). Male and female mice were analyzed together. In many

575 cases, highly penetrant phenotypes revealed the genotypes of the mice and no blinding

576 could be performed. Significance between groups was determined using unpaired two-

577 tailed Student's t-test. Data are presented as mean \pm standard error of the mean (s.e.m)

578 and statistical significance was set at alpha $=0.05(P<0.05)$. Graphical representations

579 of data and statistical analyses were performed in GraphPad Prism 8 (San Diego, CA).

\section{List of Abbreviations}

582 BAX: BCL2-associated X protein; CAM: cell adhesion molecule; $\mathrm{CB}_{1} \mathrm{R}$ : cannabinoid

583 receptor 1; CCK: cholecystokinin; CGE: caudal ganglionic eminence; cKO: conditional

584 knockout; CNS: central nervous system; GABA: gamma-aminobutyric acid; IN:

585 interneuron; MGE: medial ganglionic eminence; P: postnatal day; PV: parvalbumin;

586 PyN: pyramidal neuron; SST: somatostatin; VGLUT3; vesicular glutamate transporter 3 


\section{DECLARATIONS}

\section{Ethics approval and consent to participate}

590 All experiments were carried out in the Vollum Institute at Oregon Health and Science

591 University, an American Association of Laboratory Animal Care (AAALAC)-accredited

592 institution. Animal procedures were approved by OHSU IACUC and adhered to the NIH

593 Guide for the care and use of laboratory animals.

595 Consent for publication

596 Not applicable

598 Availability of data and materials

599 The datasets used during the current study are available from the corresponding author 600 upon request.

601

602 Authors' contributions

603 DSM and KMW designed the experiments. DSM performed experiments and analyzed

604 the data. DSM prepared the figures and wrote the original draft. DSM and KMW revised 605 and edited the final draft. Both authors read and approved the final manuscript.

606

\section{Acknowledgments}

608 This work was funded by NIH Grants R01-NS091027 (K.M.W.), CureCMD (K.M.W.), 609 NINDS P30-NS061800 (OHSU ALM), NINDS F31 NS108522 (D.S.M), and a Tartar 610 Trust Fellowship (D.S.M). 


\section{$612 \quad$ Funding}

613 Funding bodies were not involved in the design of the study or involved in collection,

614 analysis, or interpretation of data.

615

\section{Competing interests}

617 The authors declare that they have no competing interests.

\section{Authors' information}

$620{ }^{1}$ Neuroscience Graduate Program, Oregon Health \& Science University, Portland, OR

62197239

622 2Vollum Institute, Oregon Health \& Science University, 3181 SW Sam Jackson Park Rd,

623 Mailcode: L474, Portland, OR 97239, USA.

\section{REFERENCES}

1. Albayram Ö, Passlick S, Bilkei-Gorzo A, Zimmer A, Steinhäuser C. Physiological impact of CB1 receptor expression by hippocampal GABAergic interneurons. Pflugers Arch. 2016;468(4):727-37.

2. Anderson GR, Maxeiner S, Sando R, Tsetsenis T, Malenka RC, Südhof TC. Postsynaptic adhesion GPCR latrophilin-2 mediates target recognition in entorhinalhippocampal synapse assembly. J Cell Biol. 2017;216(11):3831-46.

3. Anderson SA, Eisenstat DD, Shi L, Rubenstein JL. Interneuron migration from basal forebrain to neocortex: dependence on Dlx genes. Science. 1997;278(5337):474-6.

4. Barresi R, Campbell KP. Dystroglycan: from biosynthesis to pathogenesis of human disease. J Cell Sci. 2006;119(Pt 2):199-207. 
5. Belvindrah R, Graus-Porta D, Goebbels S, Nave K-A, Müller U. Beta1 integrins in radial glia but not in migrating neurons are essential for the formation of cell layers in the cerebral cortex. J Neurosci. 2007;27(50):13854-65.

6. Berghuis P, Dobszay MB, Wang X, Spano S, Ledda F, Sousa KM, et al. Endocannabinoids regulate interneuron migration and morphogenesis by transactivating the TrkB receptor. Proc Natl Acad Sci U S A. 2005;102(52):1911520.

7. Betley JN, Wright CVE, Kawaguchi Y, Erdélyi F, Szabó G, Jessell TM, et al. Stringent specificity in the construction of a GABAergic presynaptic inhibitory circuit. Cell. 2009;139(1):161-74.

8. Boucard AA, Chubykin AA, Comoletti D, Taylor P, Südhof TC. A splice code for trans-synaptic cell adhesion mediated by binding of neuroligin 1 to alpha- and betaneurexins. Neuron. 2005;48(2):229-36.

9. Brünig I, Suter A, Knuesel I, Lüscher B, Fritschy J-M. GABAergic terminals are required for postsynaptic clustering of dystrophin but not of $G A B A(A)$ receptors and gephyrin. J Neurosci. 2002;22(12):4805-13.

10. Campanelli JT, Roberds SL, Campbell KP, Scheller RH. A role for dystrophinassociated glycoproteins and utrophin in agrin-induced AChR clustering. Cell. 1994;77(5):663-74.

11. Calvigioni D, Máté Z, Fuzik J, Girach F, Zhang M-D, Varro A, et al. Functional differentiation of cholecystokinin-containing interneurons destined for the cerebral cortex. Cereb Cortex. 2016; bhw094.

12. Carlén M, Meletis K, Siegle JH, Cardin JA, Futai K, Vierling-Claassen D, et al. A critical role for NMDA receptors in parvalbumin interneurons for gamma rhythm induction and behavior. Mol Psychiatry. 2012;17(5):537-48.

13. Carriere $\mathrm{CH}$, Wang WX, Sing AD, Fekete A, Jones BE, Yee Y, et al. The YProtocadherins regulate the survival of GABAergic interneurons during developmental cell death. J Neurosci. 2020;40(45):8652-68.

14. Chao H-T, Chen H, Samaco RC, Xue M, Chahrour M, Yoo J, et al. Dysfunction in GABA signalling mediates autism-like stereotypies and Rett syndrome phenotypes. Nature. 2010;468(7321):263-9.

15. Chen LY, Jiang M, Zhang B, Gokce O, Südhof TC. Conditional deletion of all neurexins defines diversity of essential synaptic organizer functions for neurexins. Neuron. 2017;94(3):611-625.e4. 
16. Chittajallu R, Craig MT, McFarland A, Yuan X, Gerfen S, Tricoire L, et al. Dual origins of functionally distinct O-LM interneurons revealed by differential 5-HT(3A)R expression. Nat Neurosci. 2013;16(11):1598-607.

17. Clements R, Turk R, Campbell KP, Wright KM. Dystroglycan maintains inner limiting membrane integrity to coordinate retinal development. J Neurosci. 2017;37(35):8559-74.

18. Cohn RD, Henry MD, Michele DE, Barresi R, Saito F, Moore SA, et al. Disruption of DAG1 in differentiated skeletal muscle reveals a role for dystroglycan in muscle regeneration. Cell. 2002;110(5):639-48.

19. Cope DW, Maccaferri G, Márton LF, Roberts JDB, Cobden PM, Somogyi P. Cholecystokinin-immunopositive basket and Schaffer collateral-associated interneurones target different domains of pyramidal cells in the CA1 area of the rat hippocampus. Neuroscience. 2002;109(1):63-80.

20. Davis MI, Crittenden JR, Feng AY, Kupferschmidt DA, Naydenov A, Stella N, et al. The cannabinoid-1 receptor is abundantly expressed in striatal striosomes and striosome-dendron bouquets of the substantia nigra. PLoS One. 2018;13(2):e0191436.

21. Lanerolle NC, Kim JH, Robbins RJ, Spencer DD. Hippocampal interneuron loss and plasticity in human temporal lobe epilepsy. Brain research. 1989;495(2):387-395.

22. Del Pino I, Brotons-Mas JR, Marques-Smith A, Marighetto A, Frick A, Marin O, et al. Abnormal wiring of $\mathrm{CCK}(+)$ basket cells disrupts spatial information coding. Nat Neurosci. 2017;20:784-792.

23. Río JA, Lecea L, Ferrer I, Soriano E. The development of parvalbuminimmunoreactivity in the neocortex of the mouse. Brain research Developmental brain research. 1994;81(2):247-259.

24. Río JA, Martínez A, Fonseca M, Auladell C, Soriano E. Glutamate-like immunoreactivity and fate of Cajal-Retzius cells in the murine cortex as identified with calretinin antibody. Cerebral cortex. 1995;5(1):13-21.

25. Wit J, Ghosh A. Specification of synaptic connectivity by cell surface interactions. Nat Rev Neurosci. 2016;17:22-35.

26. Dimidschstein J, Chen Q, Tremblay R, Rogers SL, Saldi G-A, Guo L, et al. A viral strategy for targeting and manipulating interneurons across vertebrate species. Nat Neurosci. 2016;19(12):1743-9.

27. Dudok B, Klein PM, Hwaun E, Lee BR, Yao Z, Fong O, et al. Alternating sources of perisomatic inhibition during behavior. Neuron. 2021;109(6):997-1012.e9. 
28. Eggan SM, Mizoguchi Y, Stoyak SR, Lewis DA. Development of cannabinoid 1 receptor protein and messenger RNA in monkey dorsolateral prefrontal cortex. Cereb Cortex. 2010;20(5):1164-74.

29. Fasano C, Rocchetti J, Pietrajtis K, Zander J-F, Manseau F, Sakae DY, et al. Regulation of the hippocampal network by VGLUT3-positive CCK- GABAergic basket cells. Front Cell Neurosci. 2017;11:140.

30. Favuzzi E, Deogracias R, Marques-Smith A, Maeso P, Jezequel J, Exposito-Alonso $\mathrm{D}$, et al. Distinct molecular programs regulate synapse specificity in cortical inhibitory circuits. Science. 2019;363(6425):413-7.

31. Földy C, Darmanis S, Aoto J, Malenka RC, Quake SR, Südhof TC. Single-cell RNAseq reveals cell adhesion molecule profiles in electrophysiologically defined neurons. Proc Natl Acad Sci U S A. 2016;113(35):E5222-31.

32. Früh S, Romanos J, Panzanelli P, Bürgisser D, Tyagarajan SK, Campbell KP, et al. Neuronal dystroglycan is necessary for formation and maintenance of functional CCK-positive basket cell terminals on pyramidal cells. J Neurosci. 2016;36(40):10296-313.

33. Fuccillo MV, Földy C, Gökce Ö, Rothwell PE, Sun GL, Malenka RC, et al. Single-cell mRNA profiling reveals cell-type-specific expression of neurexin isoforms. Neuron. 2015;87(2):326-40.

34. Gaffuri A-L, Ladarre D, Lenkei Z. Type-1 cannabinoid receptor signaling in neuronal development. Pharmacology. 2012;90(1-2):19-39.

35. Gee SH, Montanaro F, Lindenbaum MH, Carbonetto S. Dystroglycan-alpha, a dystrophin-associated glycoprotein, is a functional agrin receptor. Cell. 1994;77(5):675-86.

36. Goebbels S, Bormuth I, Bode U, Hermanson O, Schwab MH, Nave K-A. Genetic targeting of principal neurons in neocortex and hippocampus of NEX-Cre mice. Genesis. 2006;44(12):611-21.

37. Godfrey C, Clement E, Mein R, Brockington M, Smith J, Talim B, et al. Refining genotype phenotype correlations in muscular dystrophies with defective glycosylation of dystroglycan. Brain. 2007;130(Pt 10):2725-35.

38. Grimes WN, Seal RP, Oesch N, Edwards RH, Diamond JS. Genetic targeting and physiological features of VGLUT3+ amacrine cells. Vis Neurosci. 2011;28(5):38192. 
39. Guillemot F. Spatial and temporal specification of neural fates by transcription factor codes. Development. 2007;134(21):3771-80.

40. Gulyás Al, Hájos N, Freund TF. Interneurons containing calretinin are specialized to control other interneurons in the rat hippocampus. J Neurosci. 1996;16(10):3397411.

41. Hara Y, Balci-Hayta B, Yoshida-Moriguchi T, Kanagawa M, Beltrán-Valero de Bernabé D, Gündeşli $\mathrm{H}$, et al. A dystroglycan mutation associated with limb-girdle muscular dystrophy. N Engl J Med. 2011;364(10):939-46.

42. Harris KD, Hochgerner H, Skene NG, Magno L, Katona L, Bengtsson Gonzales C, et al. Classes and continua of hippocampal CA1 inhibitory neurons revealed by singlecell transcriptomics. PLoS Biol. 2018;16(6):e2006387.

43. Herkenham M, Lynn AB, Little MD, Johnson MR, Melvin LS, de Costa BR, et al. Cannabinoid receptor localization in brain. Proc Natl Acad Sci U S A. 1990;87(5):1932-6.

44. Herkenham M, Lynn AB, Johnson MR, Melvin LS, de Costa BR, Rice KC. Characterization and localization of cannabinoid receptors in rat brain: a quantitative in vitro autoradiographic study. J Neurosci. 1991;11(2):563-83.

45. Huang ZJ, Di Cristo G, Ango F. Development of GABA innervation in the cerebral and cerebellar cortices. Nat Rev Neurosci. 2007;8(9):673-86.

46. Ibraghimov-Beskrovnaya O, Ervasti JM, Leveille CJ, Slaughter CA, Sernett SW, Campbell KP. Primary structure of dystrophin-associated glycoproteins linking dystrophin to the extracellular matrix. Nature. 1992;355(6362):696-702.

47. Katona I, Sperlágh B, Sík A, Käfalvi A, Vizi ES, Mackie K, et al. Presynaptically located CB1 cannabinoid receptors regulate GABA release from axon terminals of specific hippocampal interneurons. J Neurosci. 1999;19(11):4544-58.

48. Katona I, Rancz EA, Acsady L, Ledent C, Mackie K, Hajos N, et al. Distribution of CB1 cannabinoid receptors in the amygdala and their role in the control of GABAergic transmission. J Neurosci. 2001;21(23):9506-18.

49. Kepecs A, Fishell G. Interneuron cell types are fit to function. Nature. 2014;505(7483):318-26.

50. Knudson CM, Tung KS, Tourtellotte WG, Brown GA, Korsmeyer SJ. Bax-deficient mice with lymphoid hyperplasia and male germ cell death. Science.

1995;270(5233):96-9. 
51. Krueger-Burg D, Papadopoulos T, Brose N. Organizers of inhibitory synapses come of age. Curr Opin Neurobiol. 2017;45:66-77.

52. Ledonne F, Orduz D, Mercier J, Vigier L, Grove EA, Tissir F, et al. Targeted inactivation of Bax reveals a subtype-specific mechanism of Cajal-retzius neuron death in the postnatal cerebral cortex. Cell Rep. 2016;17(12):3133-41.

53. Lee S, Hjerling-Leffler J, Zagha E, Fishell G, Rudy B. The largest group of superficial neocortical GABAergic interneurons expresses ionotropic serotonin receptors. J Neurosci. 2010;30(50):16796-808.

54. Lévi S, Grady RM, Henry MD, Campbell KP, Sanes JR, Craig AM. Dystroglycan is selectively associated with inhibitory GABAergic synapses but is dispensable for their differentiation. J Neurosci. 2002;22(11):4274-85.

55. Lewis DA, Hashimoto T, Volk DW. Cortical inhibitory neurons and schizophrenia. Nat Rev Neurosci. 2005;6(4):312-24.

56. Lim L, Mi D, Llorca A, Marín O. Development and functional diversification of cortical interneurons. Neuron. 2018;100(2):294-313.

57. Lindenmaier LB, Parmentier N, Guo C, Tissir F, Wright KM. Dystroglycan is a scaffold for extracellular axon guidance decisions. Elife. 2019;8.

58. Lu W, Bromley-Coolidge S, Li J. Regulation of GABAergic synapse development by postsynaptic membrane proteins. Brain Res Bull. 2017;129:30-42.

59. Madisen L, Zwingman TA, Sunkin SM, Oh SW, Zariwala HA, Gu H, et al. A robust and high-throughput Cre reporting and characterization system for the whole mouse brain. Nat Neurosci. 2010;13(1):133-40.

60. Mancia Leon WR, Spatazza J, Rakela B, Chatterjee A, Pande V, Maniatis T, et al. Clustered gamma-protocadherins regulate cortical interneuron programmed cell death. Elife. 2020;9.

61. Manya H, Endo T. Glycosylation with ribitol-phosphate in mammals: New insights into the O-mannosyl glycan. Biochim Biophys Acta Gen Subj. 2017;1861(10):246272.

62. Marsicano G, Lutz B. Expression of the cannabinoid receptor CB1 in distinct neuronal subpopulations in the adult mouse forebrain: CB1 expression in murine forebrain. Eur J Neurosci. 1999;11(12):4213-25.

63. Mercuri E, Messina S, Bruno C, Mora M, Pegoraro E, Comi GP, et al. Congenital muscular dystrophies with defective glycosylation of dystroglycan: a population study. Neurology. 2009;72(21):1802-9. 
64. Miczán V, Kelemen K, Glavinics JR, László ZI, Barti B, Kenesei K, et al. NECAB1 and NECAB2 are prevalent calcium-binding proteins of CB1/CCK-positive GABAergic interneurons. Cereb Cortex. 2021;31(3):1786-806.

65. Miyoshi G, Hjerling-Leffler J, Karayannis T, Sousa VH, Butt SJB, Battiste J, et al. Genetic fate mapping reveals that the caudal ganglionic eminence produces a large and diverse population of superficial cortical interneurons. J Neurosci. 2010;30(5):1582-94.

66. Miyoshi G, Young A, Petros T, Karayannis T, McKenzie Chang M, Lavado A, et al. Prox1 regulates the subtype-specific development of caudal ganglionic eminencederived GABAergic cortical interneurons. J Neurosci. 2015;35(37):12869-89.

67. Moore SA, Saito F, Chen J, Michele DE, Henry MD, Messing A, et al. Deletion of brain dystroglycan recapitulates aspects of congenital muscular dystrophy. Nature. 2002;418(6896):422-5.

68. Morozov YM, Freund TF. Postnatal development and migration of cholecystokininimmunoreactive interneurons in rat hippocampus. Neuroscience. 2003;120(4):92339.

69. Morozov YM, Freund TF. Post-natal development of type 1 cannabinoid receptor immunoreactivity in the rat hippocampus. Eur J Neurosci. 2003;18(5):1213-22.

70. Morozov YM, Torii M, Rakic P. Origin, early commitment, migratory routes, and destination of cannabinoid type 1 receptor-containing interneurons. Cereb Cortex. 2009;19:i78-89.

71. Mulder J, Aguado T, Keimpema E, Barabás K, Ballester Rosado CJ, Nguyen L, et al. Endocannabinoid signaling controls pyramidal cell specification and long-range axon patterning. Proc Natl Acad Sci U S A. 2008;105(25):8760-5.

72. Myshrall TD, Moore SA, Ostendorf AP, Satz JS, Kowalczyk T, Nguyen H, et al. Dystroglycan on radial glia end feet is required for pial basement membrane integrity and columnar organization of the developing cerebral cortex. J Neuropathol Exp Neurol. 2012;71(12):1047-63.

73. Nguyen R, Venkatesan S, Binko M, Bang JY, Cajanding JD, Briggs C, et al. Cholecystokinin-expressing interneurons of the medial prefrontal cortex mediate working memory retrieval. J Neurosci. 2020;40(11):2314-31.

74. Nickolls AR, Bönnemann CG. The roles of dystroglycan in the nervous system: insights from animal models of muscular dystrophy. Dis Model Mech. 2018;11(12):dmm035931 
75. Paul A, Crow M, Raudales R, He M, Gillis J, Huang ZJ. Transcriptional architecture of synaptic communication delineates GABAergic neuron identity. Cell.

2017;171(3):522-539.e20.

76. Pelkey KA, Chittajallu R, Craig MT, Tricoire L, Wester JC, McBain CJ. Hippocampal GABAergic inhibitory interneurons. Physiol Rev. 2017;97(4):1619-747.

77. Pelkey KA, Calvigioni D, Fang C, Vargish G, Ekins T, Auville K, et al. Paradoxical network excitation by glutamate release from VGluT3(+) GABAergic interneurons. Elife. 2020;9.

78. Peng HB, Ali AA, Daggett DF, Rauvala H, Hassell JR, Smalheiser NR. The relationship between perlecan and dystroglycan and its implication in the formation of the neuromuscular junction. Cell Adhes Commun. 1998;5(6):475-89.

79. Peron SP, Freeman J, Iyer V, Guo C, Svoboda K. A cellular resolution map of barrel cortex activity during tactile behavior. Neuron. 2015;86(3):783-99.

80. Pribiag H, Peng H, Shah WA, Stellwagen D, Carbonetto S. Dystroglycan mediates homeostatic synaptic plasticity at GABAergic synapses. Proc Natl Acad Sci U S A. 2014;111(18):6810-5.

81. Priya R, Paredes MF, Karayannis T, Yusuf N, Liu X, Jaglin X, et al. Activity regulates cell death within cortical interneurons through a calcineurin-dependent mechanism. Cell Rep. 2018;22(7):1695-709.

82. Puñal VM, Paisley CE, Brecha FS, Lee MA, Perelli RM, Wang J, et al. Large-scale death of retinal astrocytes during normal development is non-apoptotic and implemented by microglia. PLoS Biol. 2019;17(10):e3000492.

83. Reissner C, Stahn J, Breuer D, Klose M, Pohlentz G, Mormann M, et al. Dystroglycan binding to alpha-neurexin competes with neurexophilin-1 and neuroligin in the brain. J Biol Chem. 2014;289:27585-27603.

84. Rovira-Esteban L, Gunduz-Cinar O, Bukalo O, Limoges A, Brockway E, Müller K, et al. Excitation of diverse classes of cholecystokinin interneurons in the basal amygdala facilitates fear extinction. eNeuro. 2019;6(6):ENEURO.0220-19.2019.

85. Sando R, Jiang X, Südhof TC. Latrophilin GPCRs direct synapse specificity by coincident binding of FLRTs and teneurins. Science. 2019;363(6429):eaav7969.

86. Sanes JR, Zipursky SL. Synaptic specificity, recognition molecules, and assembly of neural circuits. Cell. 2020;181(6):1434-5. 
87. Sato S, Omori Y, Katoh K, Kondo M, Kanagawa M, Miyata K, et al. Pikachurin, a dystroglycan ligand, is essential for photoreceptor ribbon synapse formation. Nat Neurosci. 2008;11(8):923-31.

88. Satz JS, Ostendorf AP, Hou S, Turner A, Kusano H, Lee JC, et al. Distinct functions of glial and neuronal dystroglycan in the developing and adult mouse brain. $J$ Neurosci. 2010;30(43):14560-72.

89. Schindelin J, Arganda-Carreras I, Frise E, Kaynig V, Longair M, Pietzsch T, et al. Fiji: an open-source platform for biological-image analysis. Nat Methods. 2012;9(7):676-82.

90. Schwab MH, Druffel-Augustin S, Gass P, Jung M, Klugmann M, Bartholomae A, et al. Neuronal basic helix-loop-helix proteins (NEX, neuroD, NDRF): spatiotemporal expression and targeted disruption of the NEX gene in transgenic mice. J Neurosci. 1998;18(4):1408-18.

91. Somogyi J, Baude A, Omori Y, Shimizu H, El Mestikawy S, Fukaya M, et al. GABAergic basket cells expressing cholecystokinin contain vesicular glutamate transporter type 3 (VGLUT3) in their synaptic terminals in hippocampus and isocortex of the rat. Eur J Neurosci. 2004;19(3):552-69.

92. Southwell DG, Paredes MF, Galvao RP, Jones DL, Froemke RC, Sebe JY, et al. Intrinsically determined cell death of developing cortical interneurons. Nature. 2012;491(7422):109-13.

93. Südhof TC. Towards an understanding of synapse formation. Neuron. 2018;100(2):276-93.

94. Sugita S, Saito F, Tang J, Satz J, Campbell K, Südhof TC. A stoichiometric complex of neurexins and dystroglycan in brain. J Cell Biol. 2001;154(2):435-45.

95. Szabó GG, Papp OI, Máté Z, Szabó G, Hájos N. Anatomically heterogeneous populations of CB1 cannabinoid receptor-expressing interneurons in the CA3 region of the hippocampus show homogeneous input-output characteristics: CB1Expressing Interneurons in CA3. Hippocampus. 2014;24(12):1506-23.

96. Tai Y, Gallo NB, Wang M, Yu J-R, Van Aelst L. Axo-axonic innervation of neocortical pyramidal neurons by GABAergic chandelier cells requires AnkyrinG-associated L1CAM. Neuron. 2019;102(2):358-372.e9.

97. Tamamaki N, Fujimori KE, Takauji R. Origin and route of tangentially migrating neurons in the developing neocortical intermediate zone. J Neurosci. 1997;17(21):8313-23. 
98. Taniguchi H, He M, Wu P, Kim S, Paik R, Sugino K, et al. A resource of Cre driver lines for genetic targeting of GABAergic neurons in cerebral cortex. Neuron. 2011;71(6):995-1013.

99. Taniguchi-Ikeda M, Morioka I, lijima K, Toda T. Mechanistic aspects of the formation of alpha-dystroglycan and therapeutic research for the treatment of alphadystroglycanopathy: A review. Molecular Aspects of Medicine. 2016;51:115-124.

100. Tasic B, Menon V, Nguyen TN, Kim TK, Jarsky T, Yao Z, et al. Adult mouse cortical cell taxonomy revealed by single cell transcriptomics. Nat Neurosci. 2016;19(2):335-46.

101. Tien N-W, Soto F, Kerschensteiner D. Homeostatic plasticity shapes cell-typespecific wiring in the retina. Neuron. 2017;94(3):656-665.e4.

102. Tricoire L, Pelkey KA, Erkkila BE, Jeffries BW, Yuan X, McBain CJ. A blueprint for the spatiotemporal origins of mouse hippocampal interneuron diversity. $\mathrm{J}$ Neurosci. 2011;31(30):10948-70.

103. Tsou K, Brown S, Sañudo-Peña MC, Mackie K, Walker JM. Immunohistochemical distribution of cannabinoid CB1 receptors in the rat central nervous system. Neuroscience. 1998;83(2):393-411.

104. Uezu A, Hisey E, Kobayashi Y, Gao Y, Bradshaw TW, Devlin P, et al. Essential role for InSyn1 in dystroglycan complex integrity and cognitive behaviors in mice. Elife. 2019;8.

105. Urbán Z, Maglóczky Z, Freund TF. Calretinin-containing interneurons innervate both principal cells and interneurons in the CA1 region of the human hippocampus. Acta Biol Hung. 2002;53(1-2):205-20.

106. Van Waes V, Beverley JA, Siman H, Tseng KY, Steiner H. CB1 cannabinoid receptor expression in the striatum: Association with corticostriatal circuits and developmental regulation. Front Pharmacol. 2012;3:21.

107. Vargish GA, Pelkey KA, Yuan X, Chittajallu R, Collins D, Fang C, et al. Persistent inhibitory circuit defects and disrupted social behaviour following in utero exogenous cannabinoid exposure. Mol Psychiatry. 2017;22(1):56-67.

108. Verret L, Mann EO, Hang GB, Barth AMI, Cobos I, Ho K, et al. Inhibitory interneuron deficit links altered network activity and cognitive dysfunction in Alzheimer model. Cell. 2012;149(3):708-21.

109. Vitalis T, Lainé J, Simon A, Roland A, Leterrier C, Lenkei Z. The type 1 cannabinoid receptor is highly expressed in embryonic cortical projection neurons 
and negatively regulates neurite growth in vitro. Eur J Neurosci. 2008;28(9):170518.

110. Whissell PD, Cajanding JD, Fogel N, Kim JC. Comparative density of CCK- and PV-GABA cells within the cortex and hippocampus. Front Neuroanat. 2015;9:124.

111. Whissell PD, Bang JY, Khan I, Xie Y-F, Parfitt GM, Grenon M, et al. Selective activation of cholecystokinin-expressing GABA (CCK-GABA) neurons enhances memory and cognition. eNeuro. 2019;6(1):ENEURO.0360-18.2019.

112. White FA, Keller-Peck CR, Knudson CM, Korsmeyer SJ, Snider WD. Widespread elimination of naturally occurring neuronal death in Bax-deficient mice. J Neurosci. 1998;18(4):1428-39.

113. Wright KM, Lyon KA, Leung H, Leahy DJ, Ma L, Ginty DD. Dystroglycan organizes axon guidance cue localization and axonal pathfinding. Neuron. 2012;76(5):931-44.

114. Wu S-X, Goebbels S, Nakamura K, Nakamura K, Kometani K, Minato N, et al. Pyramidal neurons of upper cortical layers generated by NEX-positive progenitor cells in the subventricular zone. Proc Natl Acad Sci U S A. 2005;102(47):17172-7.

115. Xu C, Theisen E, Maloney R, Peng J, Santiago I, Yapp C, et al. Control of synaptic specificity by establishing a relative preference for synaptic partners. Neuron. 2019;106(2):355.

116. Yoshida-Moriguchi T, Campbell KP. Matriglycan: a novel polysaccharide that links dystroglycan to the basement membrane. Glycobiology. 2015;25(7):702-13.

117. Zaccaria ML, Di Tommaso F, Brancaccio A, Paggi P, Petrucci TC. Dystroglycan distribution in adult mouse brain: a light and electron microscopy study. Neuroscience. 2001;104(2):311-24.

118. Zecevic N, Hu F, Jakovcevski I. Interneurons in the developing human neocortex. Dev Neurobiol. 2011;71(1):18-33.

119. Zeisel A, Muñoz-Manchado AB, Codeluppi S, Lönnerberg P, La Manno G, Juréus $A$, et al. Brain structure. Cell types in the mouse cortex and hippocampus revealed by single-cell RNA-seq. Science. 2015;347(6226):1138-42. 


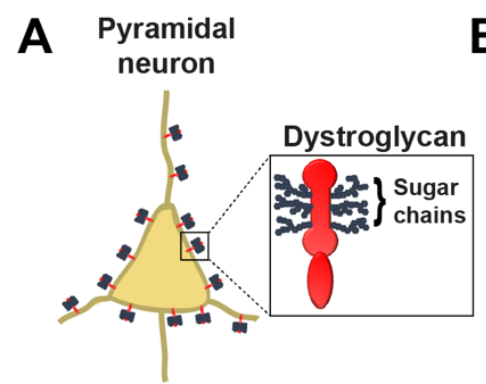

B $\mathrm{Nex}^{\mathrm{Cre}} ; \mathrm{Dag} 1^{\text {+/ }}$

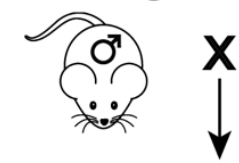

$\operatorname{Dag} 1^{F / 4} ; \mathrm{Nex}^{\mathrm{Cre}}\left(\operatorname{Dag} 1^{\text {Control }}\right)$ $\operatorname{Dag}^{\mathrm{F} / \mathrm{Nex}^{\mathrm{Cre}}}\left(\mathrm{Dag}^{\left.1 \mathrm{CKO}^{\mathrm{K}}\right)}\right.$
C
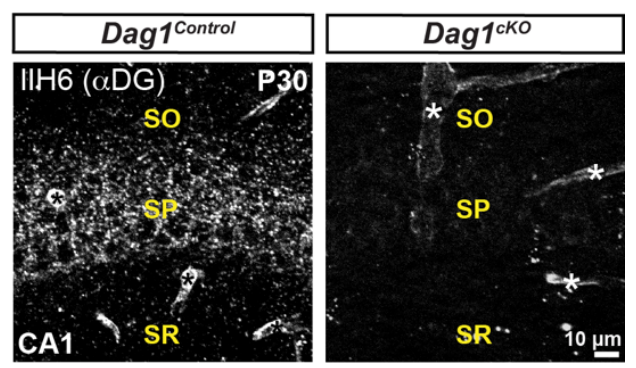

D

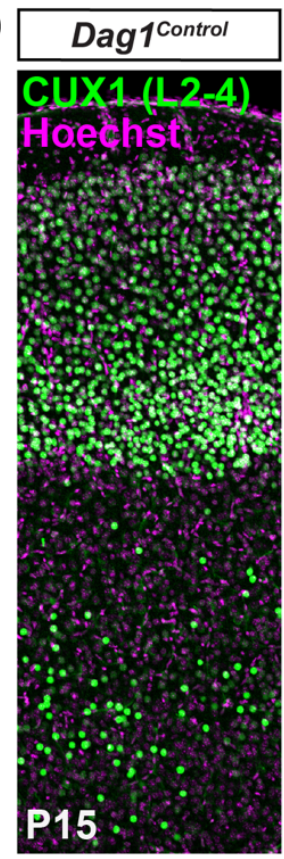

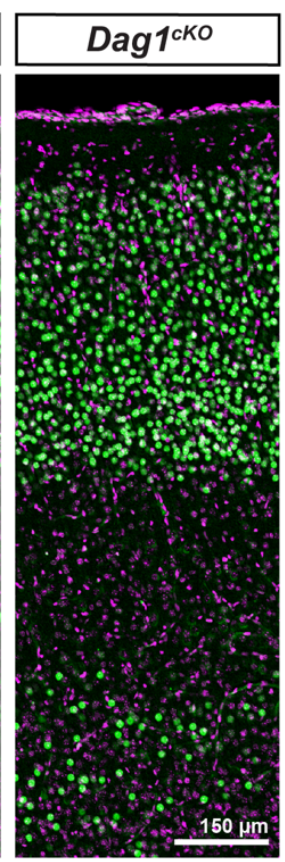
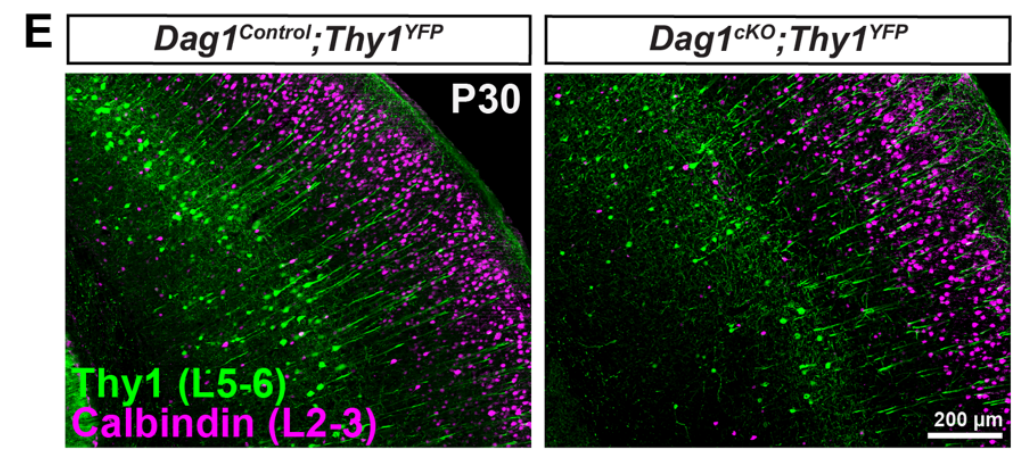

$\mathbf{F}$
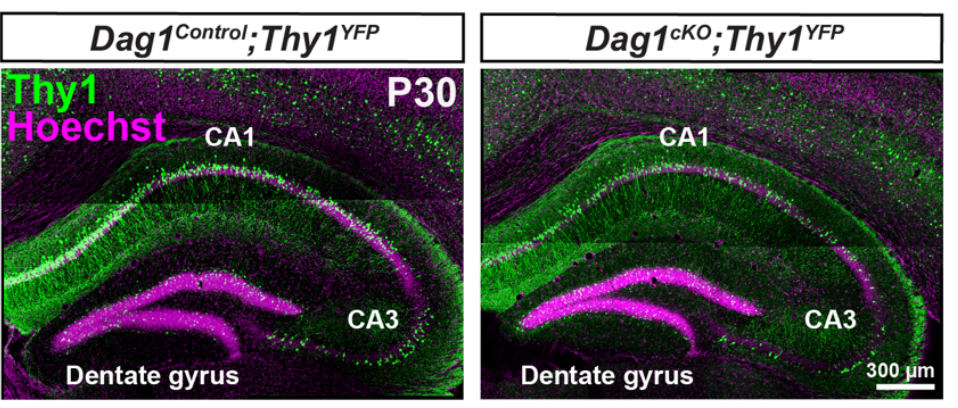

Figure 1. Neuronal Dystroglycan is not required for pyramidal neuron migration.

(A) Schematic of Dystroglycan on pyramidal neurons. Inset shows the structure of Dystroglycan and sugar chain moieties present on the extracellular subunit. (B) Mouse breeding scheme for generating pyramidal neuron-specific Dag1 conditional knockout mice using $\mathrm{Nex}^{\mathrm{Cre}}$ driver mice. (C) Immunostaining for Dystroglycan in the hippocampal

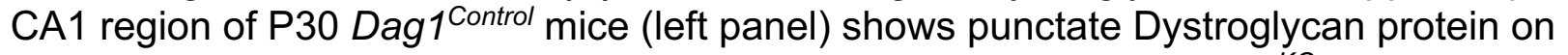
the soma and proximal dendrites of pyramidal neurons, whereas Dag1 ${ }^{\text {cKO }}$ mice (right panel) lack perisomatic staining. Asterisks denote Dystroglycan staining on blood vessels which is retained in Dag ${ }^{\text {cKO }}$ mice. (D) Coronal sections from P15 Dag $1^{\text {Control }}$ and Dag $1^{1 K O}$ cortex were immunostained for upper layer marker CUX1 (L2-4). (E) Coronal sections of the cortex from P30 Dag $1^{\text {Control }}$ and Dag $1^{\text {cKO }}$ mice crossed with a Thy $1^{\text {YFP }}$ reporter mouse to sparsely label layer 5-6 pyramidal neurons (green) and stained for Calbindin (magenta) to label layer 2-3 pyramidal neurons. (F) Coronal sections of the hippocampus from P30 Dag $1^{\text {Control }}$ and Dag $1^{\text {cKO }}$ mice crossed with a Thy $1^{\text {YFP }}$ reporter mouse to label excitatory neurons (green) in the CA regions and dentate gyrus. 

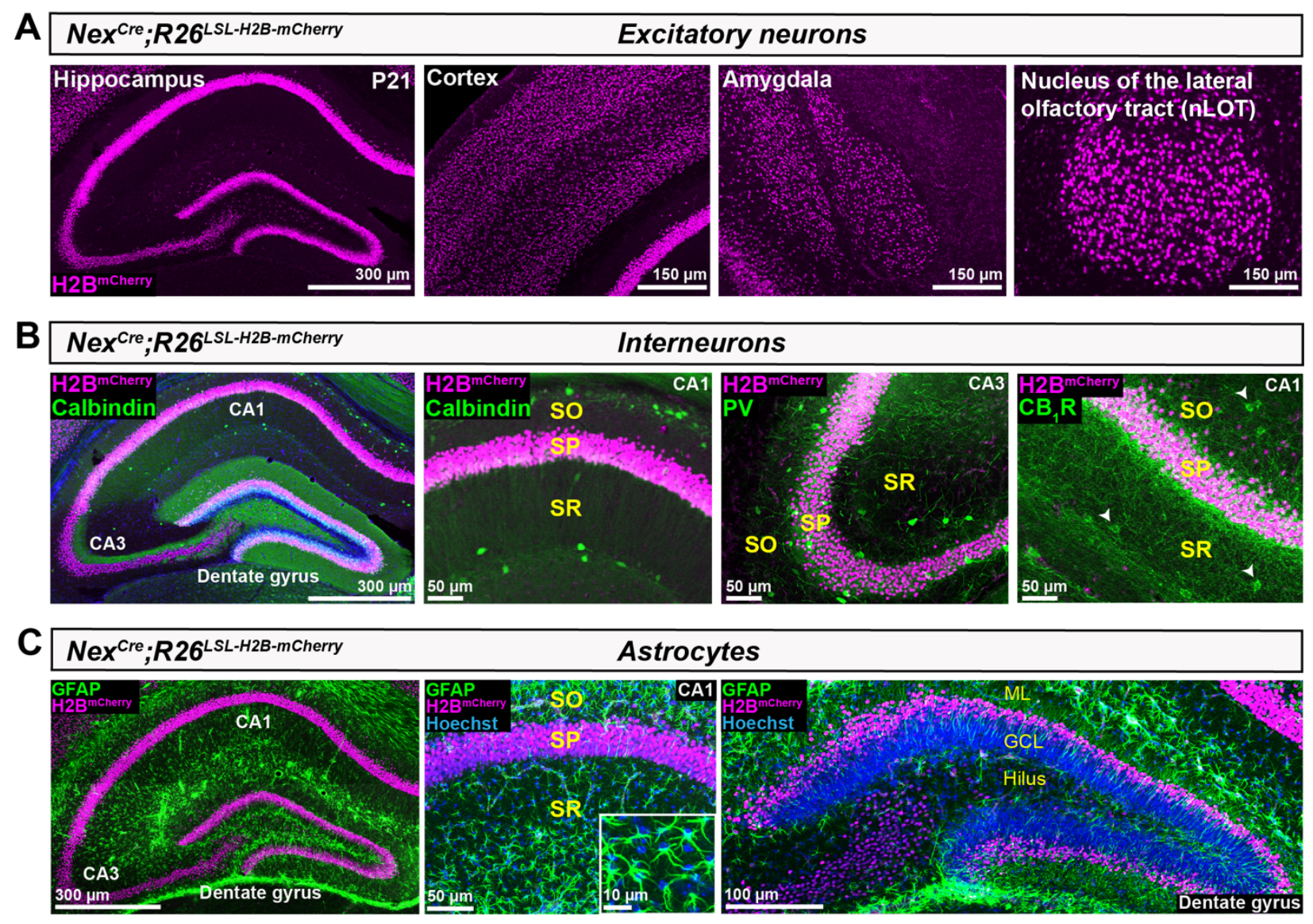

Figure S1. Nex ${ }^{\text {Cre }}$ drives recombination in forebrain pyramidal neurons but not interneurons or glia. (A) Coronal sections from Nex ${ }^{C r e} ; R 26^{L S L-H 2 B-m C h e r r y}$ reporter mice at P21 show mCherry+ nuclei (magenta) of pyramidal neurons in the hippocampus, cortex, amygdala, and nucleus of the lateral olfactory tract (nLOT). (B) Hippocampal sections from $\mathrm{Nex}{ }^{\mathrm{Cre}} ; R 26^{L S L-H 2 B-m C h e r r y}$ reporter mice immunostained for interneuron markers (green) Calbindin (left panels), Parvalbumin (middle panel), and $\mathrm{CB}_{1} \mathrm{R}$ (right panel) show no overlap of interneuron cell bodies with mCherry+ nuclei. White arrowheads indicate $\mathrm{CB}_{1} \mathrm{R}+$ cell bodies. SO, stratum oriens; $\mathrm{SP}$, stratum pyramidale; $\mathrm{SR}$, stratum radiatum. (C) The astrocyte marker GFAP (green) shows no overlap with mCherry+ nuclei in the hippocampal CA regions or dentate gyrus (left and middle panels). Inset (middle panel) shows a magnified view of astrocyte nuclei (blue). mCherry+ nuclei occupy the outer third of the dentate gyrus granule cell layer (right panel). ML, molecular layer; GCL, granule cell layer. 


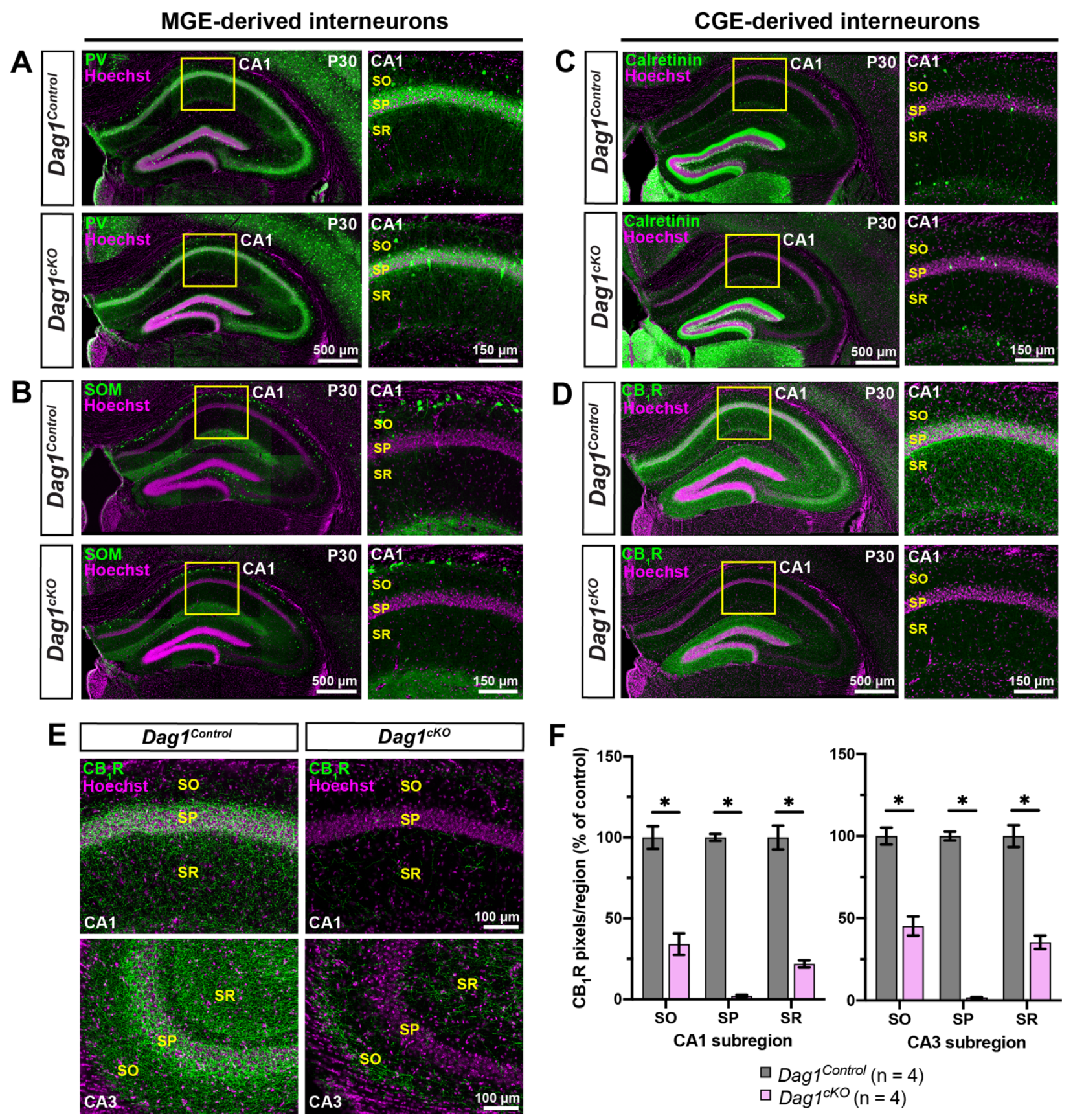

Figure 2. CCK+ interneurons are selectively reduced in mice lacking Dystroglycan from pyramidal neurons. (A-B) Immunostaining for medial ganglionic eminence (MGE)-derived interneuron markers (green) parvalbumin (PV) (A) and somatostatin (SOM) (B) show normal innervation of the hippocampus in P30 Dag $1^{\text {Control }}$ and Dag1 ${ }^{\text {cKO }}$ mice. Insets (yellow boxed regions) show enlarged images of the CA1. (C-D) Immunostaining for caudal ganglionic eminence (CGE)-derived interneuron markers (green) Calretinin (C), and $\mathrm{CB}_{1} \mathrm{R}(\mathrm{D})$ show normal innervation of Calretinin interneurons in $D a g{ }_{1}{ }^{\text {Control }}$ and $D a g 1^{1 K O}$ mice, whereas $\mathrm{CB}_{1} \mathrm{R}$ is largely absent from the $\mathrm{CA}$ regions of $D a g 1^{1 K O}$ mice. Insets (yellow boxed regions) show enlarged images of the CA1. (E) Immunostaining for $\mathrm{CB}_{1} \mathrm{R}$ in hippocampal $\mathrm{CA} 1$ (top) and CA3 (bottom) of P30 Dag ${ }^{\text {Control }}$ 
and Dag1 ${ }^{1 K O}$ mice. (F) Quantification of $\mathrm{CB}_{1} \mathrm{R}$ pixels for each $\mathrm{CA}$ layer of the $\mathrm{CA} 1$ and CA3 shows a significant reduction in $\mathrm{CB}_{1} \mathrm{R}$ staining in Dag $1{ }^{c K O}$ mice $\left({ }^{*} P<0.05\right.$, unpaired two-tailed Student's t-test; $n=4$ mice/genotype). Data are presented as mean values \pm s.e.m. Data are normalized to Dag $1^{\text {Control }}$ signal in each CA layer. CA layers: $\mathrm{SO}$, stratum oriens; SP, stratum pyramidale; SR, stratum radiatum. 

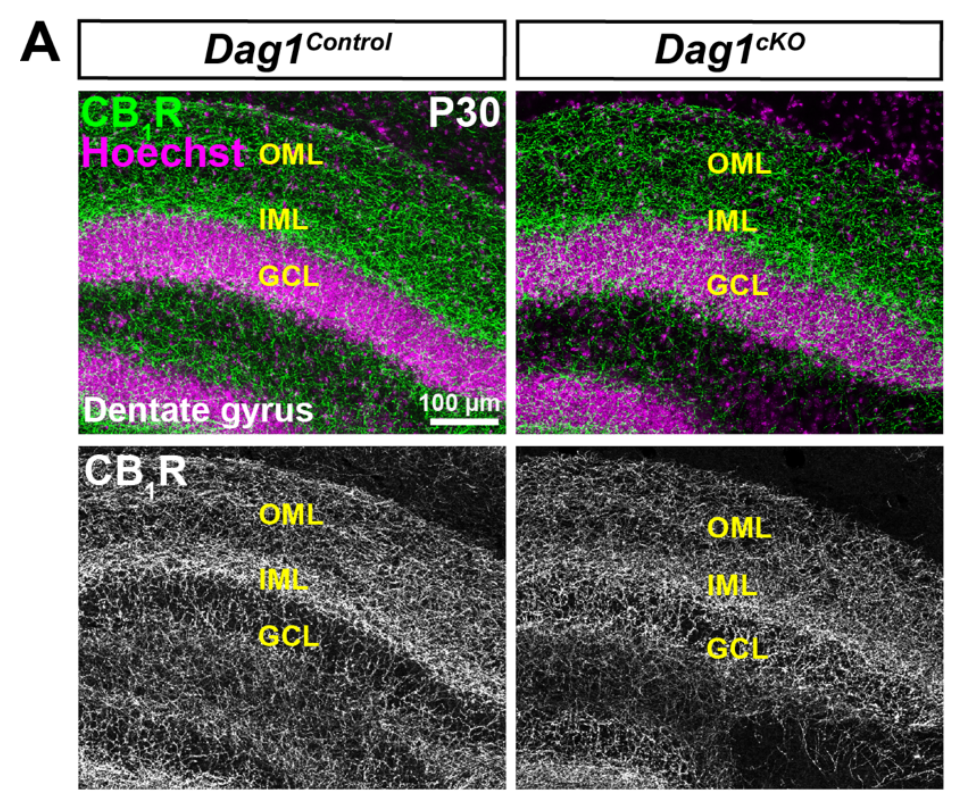
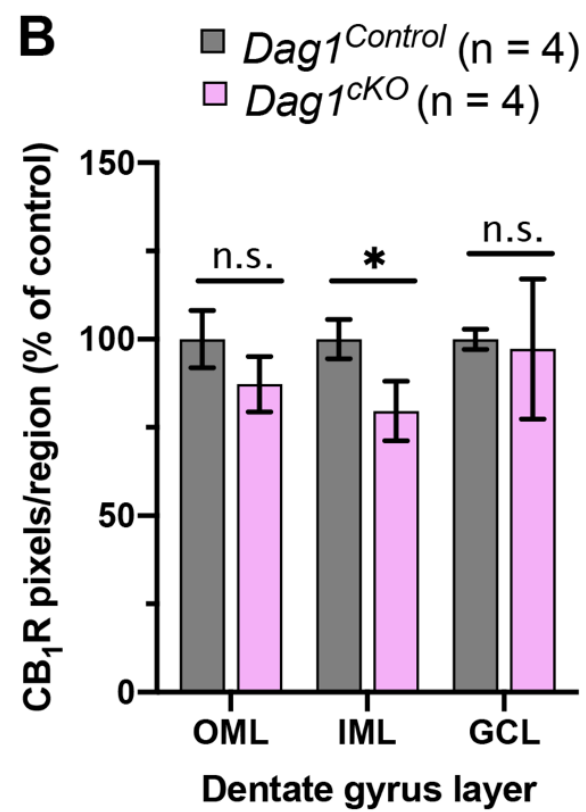

Figure S2. CCK+ interneuron innervation of the dentate gyrus is minimally altered in Dag $1^{\text {cKo }}$ mice. (A) Immunostaining of $\mathrm{CB}_{1} \mathrm{R}$ in the dentate gyrus from P30 Dag1 ${ }^{\text {Control }}$ (left panels) and $D a g 1^{c K O}$ mice (right panels). Single channel images of $C_{1} B_{1} R$ (gray) are shown below. (B) Quantification of $\mathrm{CB}_{1} \mathrm{R}$ pixels for each dentate gyrus layer $\left({ }^{*} P<0.05\right.$, unpaired two-tailed Student's t-test; $n=4$ mice/genotype). Data are presented as mean values \pm s.e.m. Data are normalized to Dag $1^{\text {Control }}$ signal in each dentate gyrus layer. OML, outer molecular layer; IML, inner molecular layer; GCL, granule cell layer. 
A

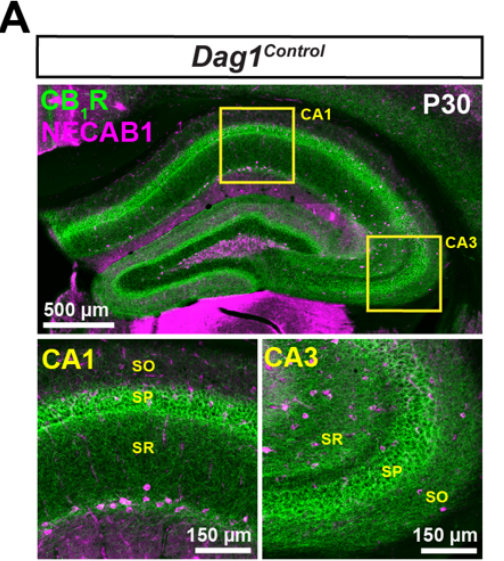

$\mathbf{C}$

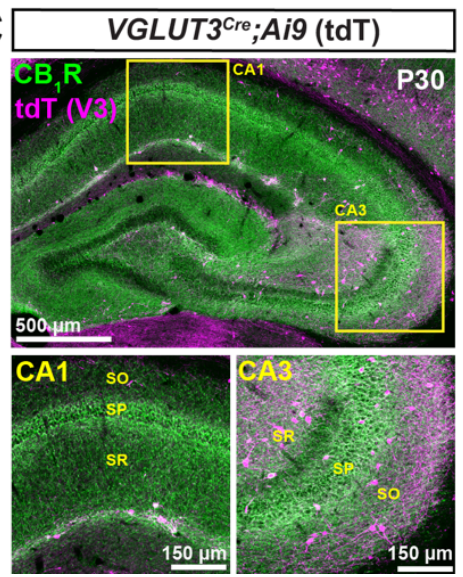

B
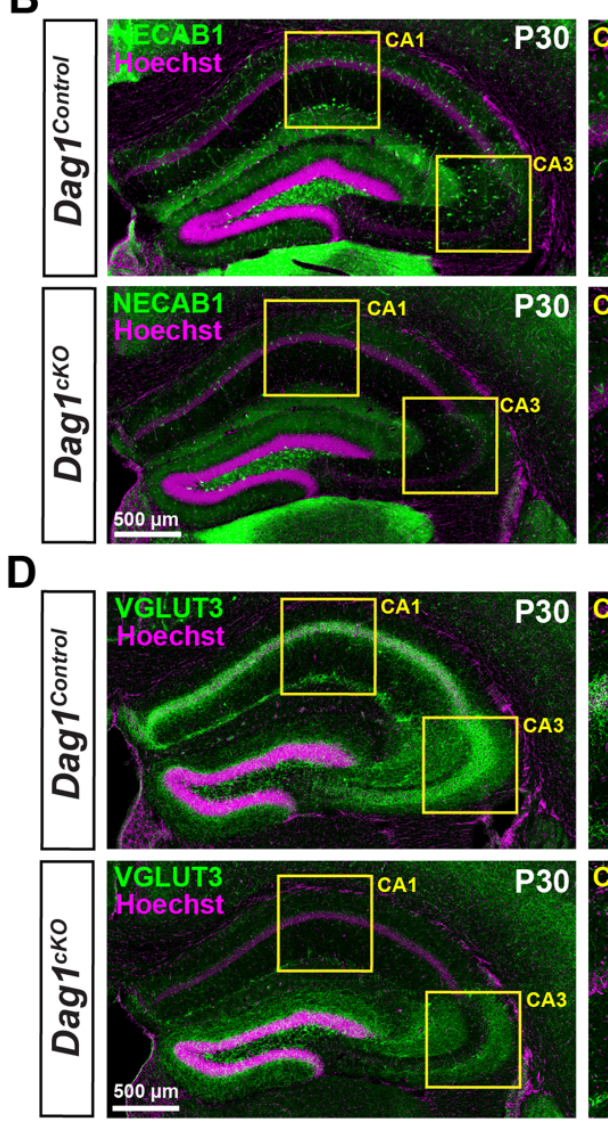
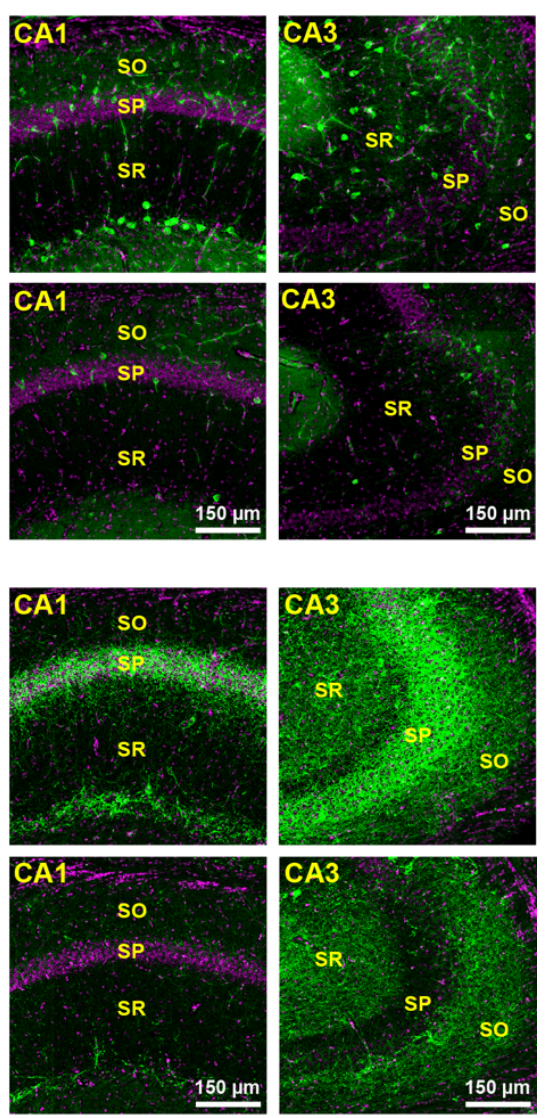

Figure 3. Cell body and synaptic markers for CCK+ interneurons are reduced in Dag $1^{\text {cKo }}$ mice. (A) Immunostaining showing the co-localization of $\mathrm{CB}_{1} \mathrm{R}$ (green) and NECAB1 (magenta) in CCK+ interneurons. Insets (yellow boxed regions) show enlarged images of the CA1 and CA3. (B) Immunostaining for NECAB1 (green) shows a reduction of NECAB1+ interneurons in the hippocampus of P30 Dag ${ }^{\text {cKO }}$ mice. Insets (yellow boxed regions) show enlarged images of the CA1 and CA3. (C) Immunostaining of hippocampal sections from VGLUT3 ${ }^{\text {Cre }}$ mice crossed with a Lox-STOP-Lox-tdTomato (Ai9) reporter mouse showing the co-localization of $\mathrm{CB}_{1} \mathrm{R}$ (green) and VGLUT3 (magenta) in a subset of CCK+ interneurons. Insets (yellow boxed regions) show enlarged images of the CA1 and CA3. (D) Immunostaining for VGLUT3 (green) shows a reduction of $\mathrm{CCK}+$ interneuron synaptic terminals in the hippocampus of P30 Dag $1^{\text {cKO }}$ mice. Insets (yellow boxed regions) show enlarged images of the CA1 and CA3. CA layers: SO, stratum oriens; SP, stratum pyramidale; SR, stratum radiatum. 

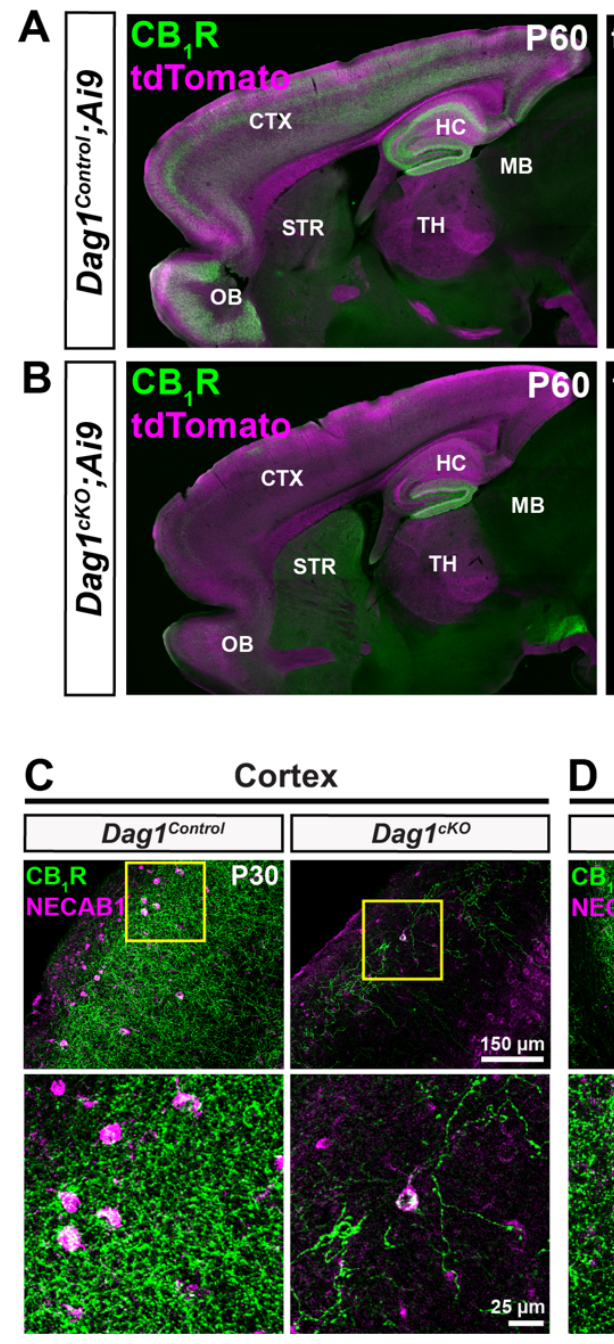
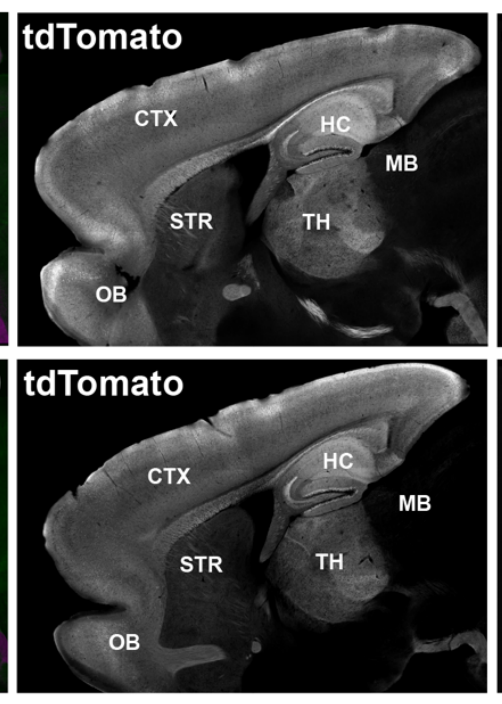

D

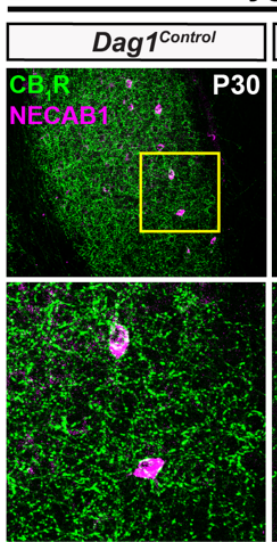

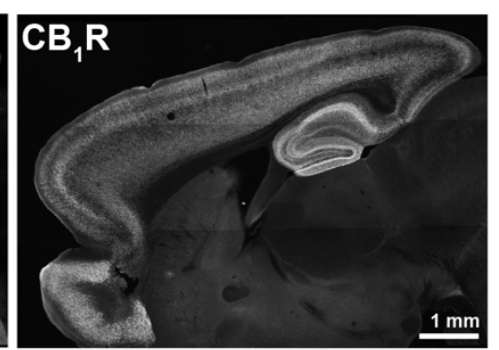

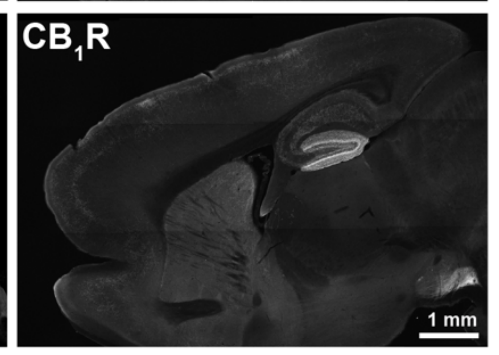

Nucleus of the lateral E - olfactory tract (nLOT)

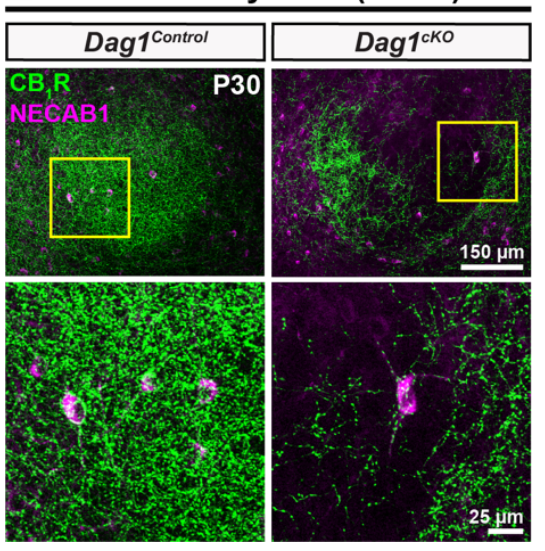

Figure 4. $\mathrm{CCK}+$ interneurons are reduced throughout the forebrain of mice lacking Dystroglycan from pyramidal neurons. (A-B) Sagittal sections from P60 Dag ${ }^{\text {Control; }}$ Ai9 (A) and Dag ${ }^{\text {cKO; }}$;Ai9 mice (B) immunostained for $\mathrm{CB}_{1} \mathrm{R}$ (green; right panels) and tdTomato/Ai9 (magenta; middle panels). In Dag1 ${ }^{\text {cKO; }}$;i9 mice, $\mathrm{CB}_{1} \mathrm{R}$ staining is lacking in all the forebrain regions where $\mathrm{Nex}$ Cre drives recombination in excitatory neurons (tdTomato expression, middle panels) including the cortex (CTX), hippocampus $(\mathrm{HC})$, and olfactory bulb (OB). Note the absence of tdTomato signal in the striatum (STR) and midbrain (MB), which are not targeted by $\mathrm{Nex}^{\mathrm{Cre}}$. (C-E) Immunostaining for $\mathrm{CB}_{1} \mathrm{R}$ (green) and NECAB1 (magenta) in the cortex (C), amygdala (D), and nucleus of the lateral olfactory tract $(E)$ shows the reduction of CCK+ interneuron markers in the forebrain of P30 Dag $1^{\text {cKO }}$ mice (right panels). Enlarged images (yellow boxed regions) show individual NECAB1+ cell bodies (magenta) colocalized with $\mathrm{CB}_{1} \mathrm{R}$ (green). 
A
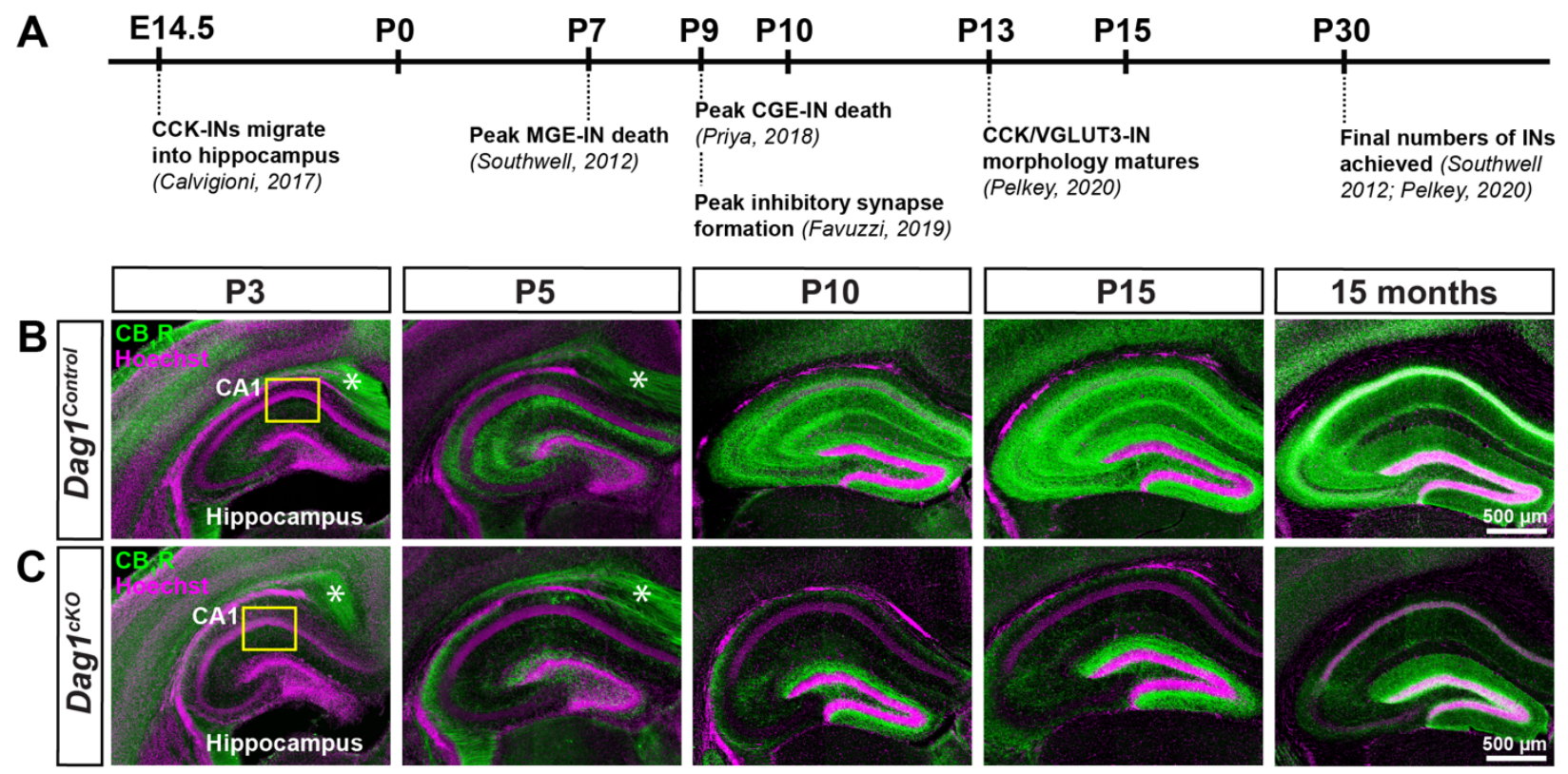

Peak inhibitory synapse formation (Favuzzi, 2019)
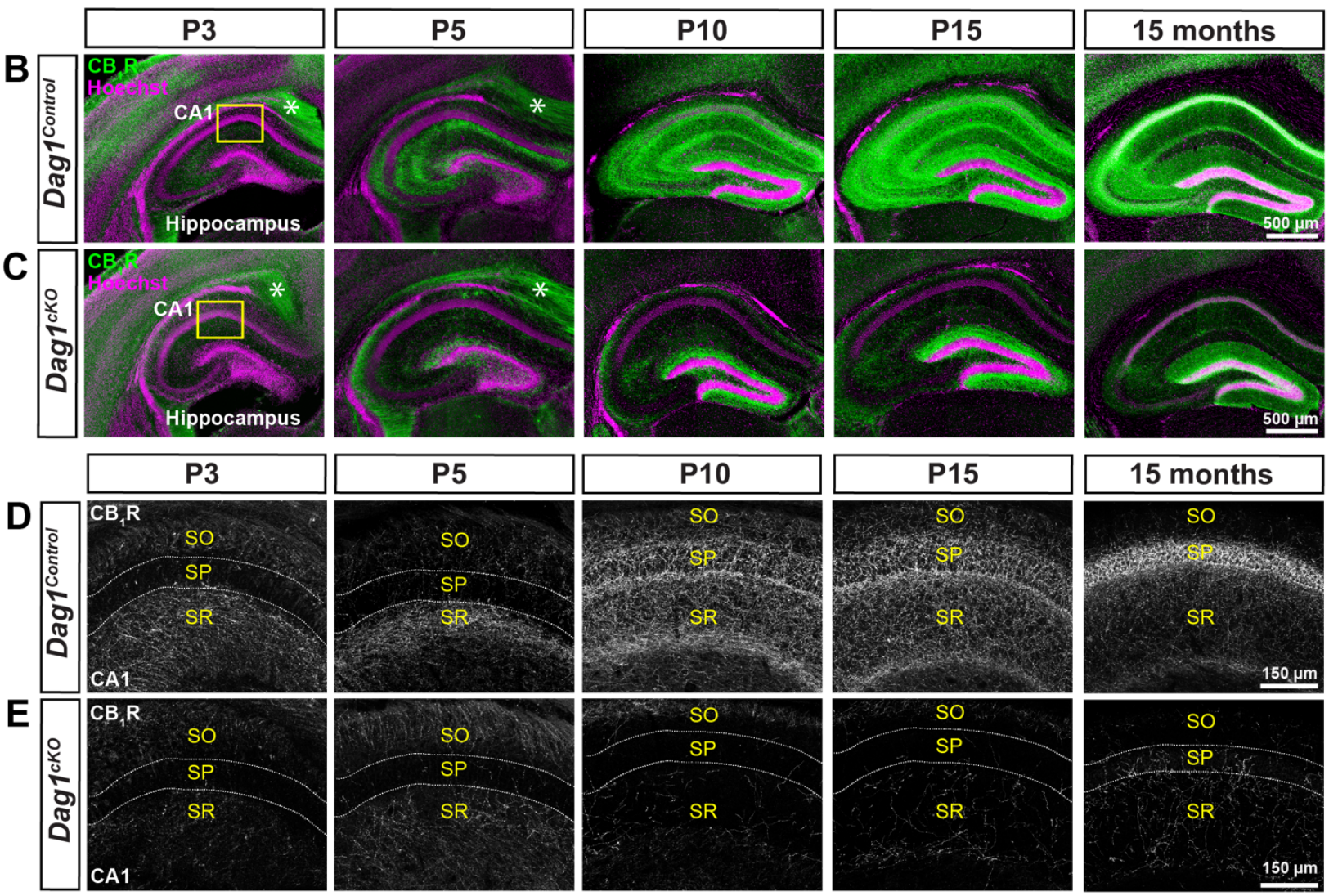

$\mathbf{F}$

P3

P5

P10

P15

$15 \mathrm{mo}$.
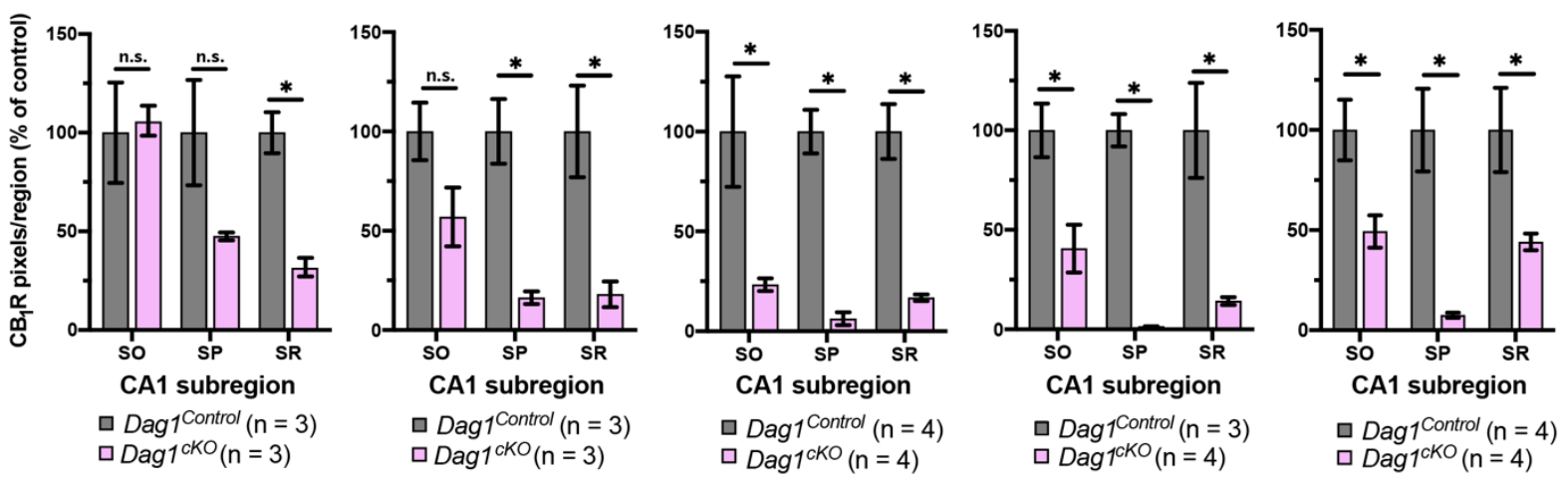

Figure 5. Postnatal development of CCK+ interneurons is impaired in the hippocampus of Dag ${ }^{c K O}$ mice. (A) Timeline of interneuron developmental milestones including interneuron migration, cell death, and inhibitory synapse formation. (B-C) Immunostaining for $\mathrm{CB}_{1} \mathrm{R}$ (green) in the hippocampus of Dag $1^{\text {Control mice }}(\mathrm{B})$ shows a progressive increase in CCK+ interneuron axon terminals from P3-P15. In contrast, 
$\mathrm{CB}_{1} \mathrm{R}+$ axon terminals are diminished at all ages in Dag $1^{\mathrm{ckO}}$ mice (C). Asterisks (P3 and $\mathrm{P} 5)$ denote the presence of $\mathrm{CB}_{1} \mathrm{R}$ immunoreactivity in pyramidal neuron axons at early postnatal ages. Yellow boxes (B, C) indicate approximate locations of high magnification images in (D-E). High magnification (20X), single channel images (gray) of $\mathrm{CB}_{1} \mathrm{R}+$ axon terminals in the CA1 of $D a g{ }^{\text {Control }}(\mathbf{D})$ and $D a g 1^{\mathrm{cKO}}$ mice $(\mathrm{E})$ from P3-15 months. Dotted white lines indicate the position of the pyramidal cell layer (SP). SO, stratum oriens; SP, stratum pyramidale; SR, stratum radiatum. (F) Quantification of $\mathrm{CB}_{1} \mathrm{R}$ pixels in hippocampal CA1 layers from Dag $1^{\text {Control }}$ (gray) and Dag ${ }^{\mathrm{CKO}}$ (pink) mice shows significantly reduced $\mathrm{CB}_{1} \mathrm{R}$ staining at all ages examined $\left({ }^{*} P<0.05\right.$, unpaired two-tailed Student's t-test; $n=3-4$ mice/genotype). Data are presented as mean values \pm s.e.m. Data are normalized to Dag ${ }^{1 \text { Control }}$ signal in each CA layer. 


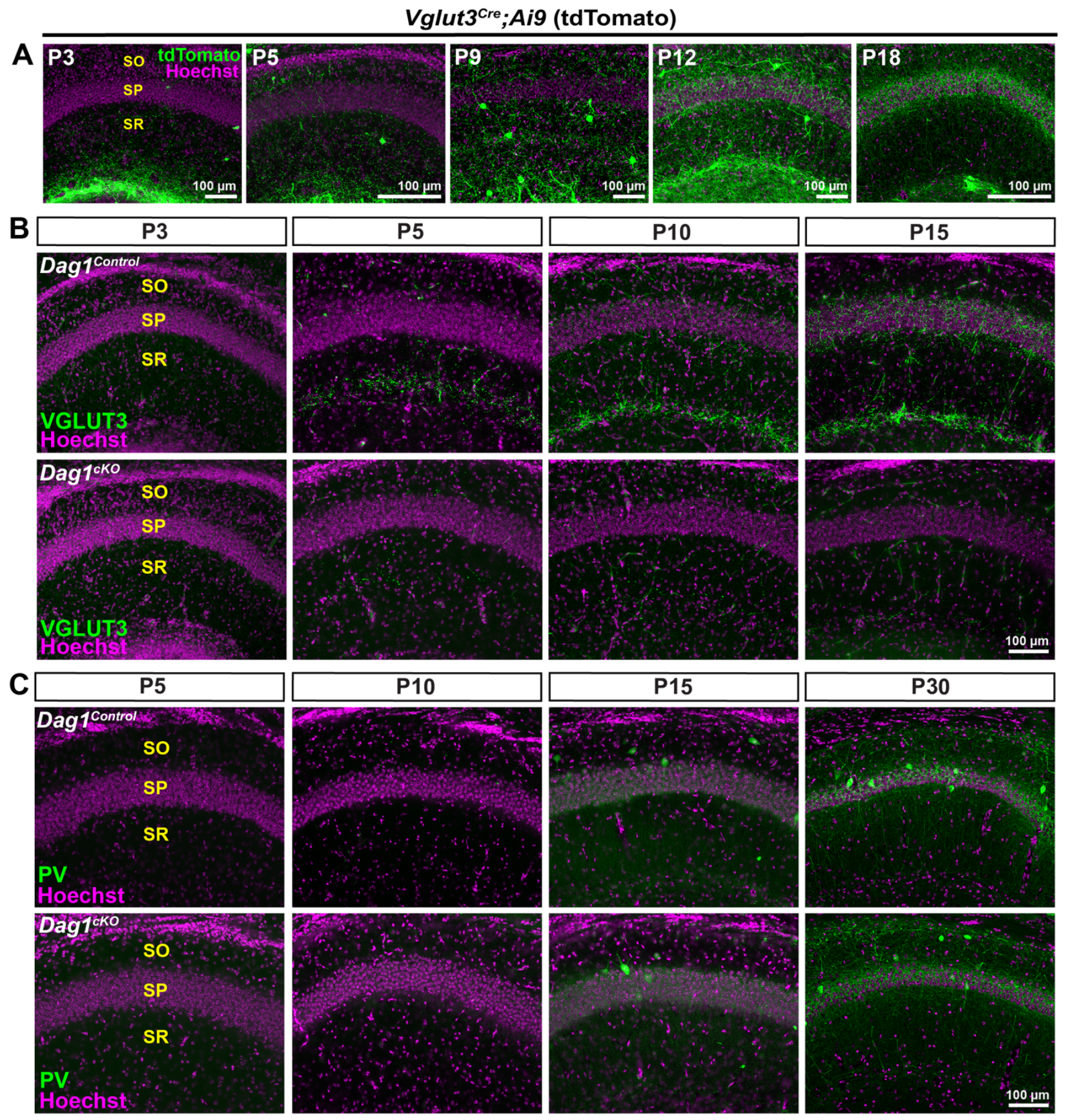

Figure S3. CCK+ interneuron markers are reduced postnatally in Dag1 ${ }^{\mathrm{ckO}}$ mice. (A) Images of hippocampal CA1 from VGLUT3 ${ }^{\text {Cre }}$;Ai9 mice from P3-P18. Immunostaining for tdTomato (green) shows progressive increase in VGLUT3 expression in the pyramidal cell layer (SP, magenta). (B) Immunostaining for VGLUT3 in the CA1 of Dag $1^{\text {Control }}$ (top panels) and Dag $1^{\mathrm{cKO}}$ mice (bottom panels) from P3-P15. Note the lack of VGLUT3 expression at all ages in Dag $1^{c K O}$ mice. (C) Parvalbumin (PV)

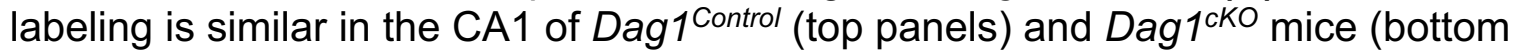
panels) from P5-P30. 
A

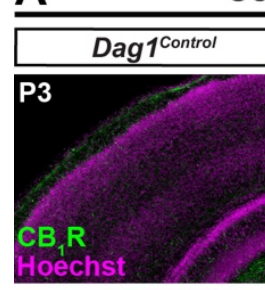

P5
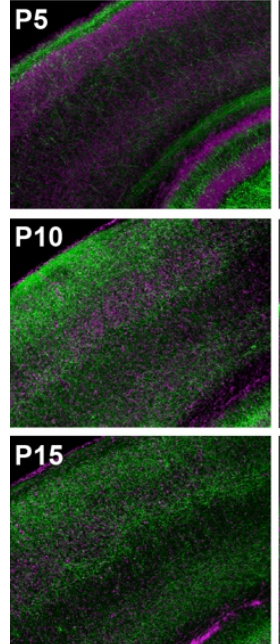

15 mo.
B
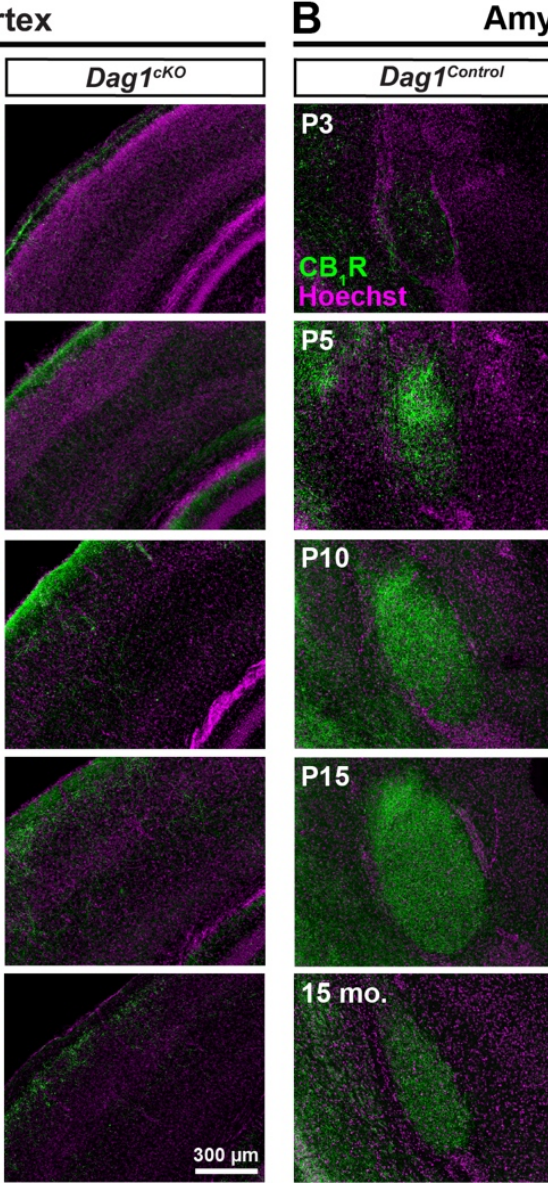
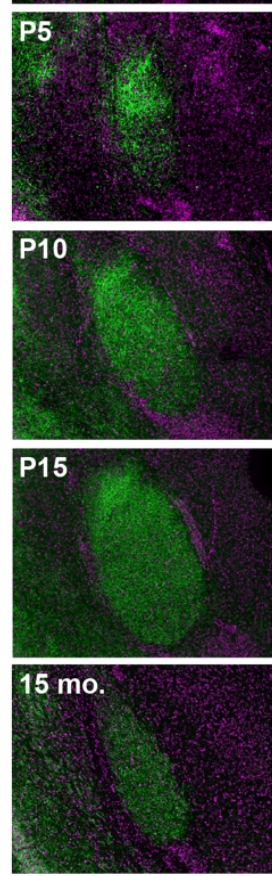

Amygdala
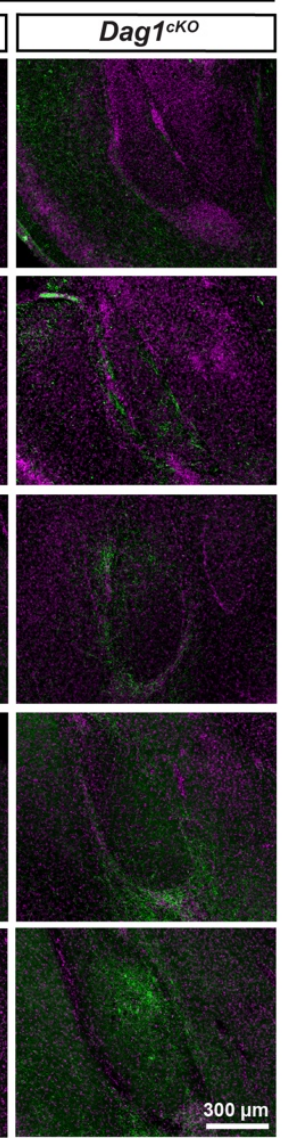

Nucleus of the lateral C olfactory tract (nLOT)
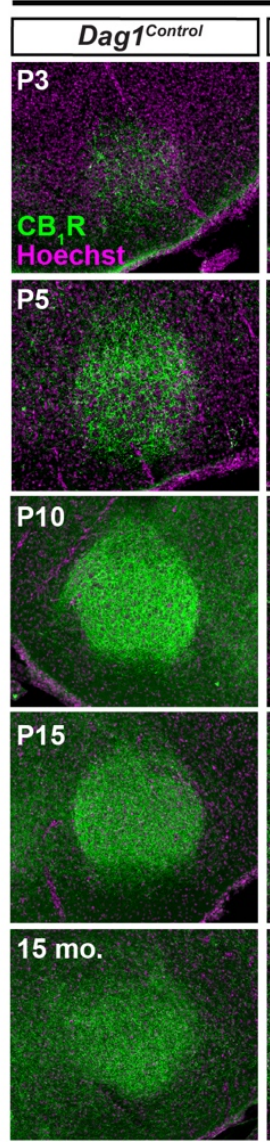

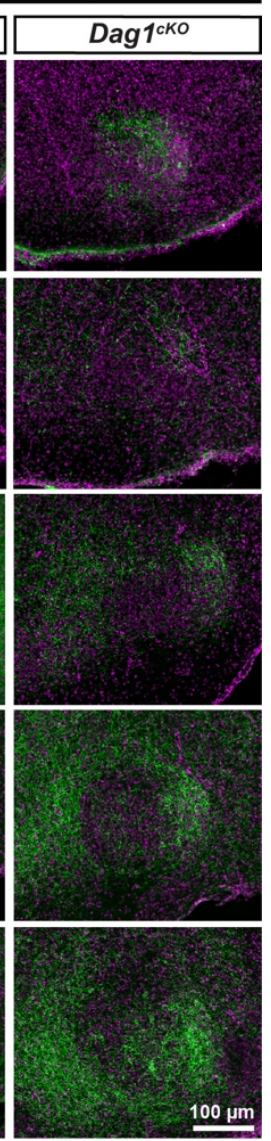

Figure 6. Postnatal development of $\mathrm{CCK}+$ interneurons is impaired in the forebrain of Dag1 ${ }^{c K O}$ mice. (A-C) Immunostaining for $\mathrm{CB}_{1} \mathrm{R}$ (green) and Hoechst (magenta) shows the progressive innervation of the cortex (A), amygdala (B), and nucleus of the lateral olfactory tract (C) of Dag1 ${ }^{\text {Control }}$ (left panels) mice by CCK+ interneurons from P3-P15. $\mathrm{CB}_{1} \mathrm{R}$ staining is decreased in all regions of $D a g 1^{\mathrm{ckO}}$ mice (right panels) at all ages examined from P3-15 months. 
A
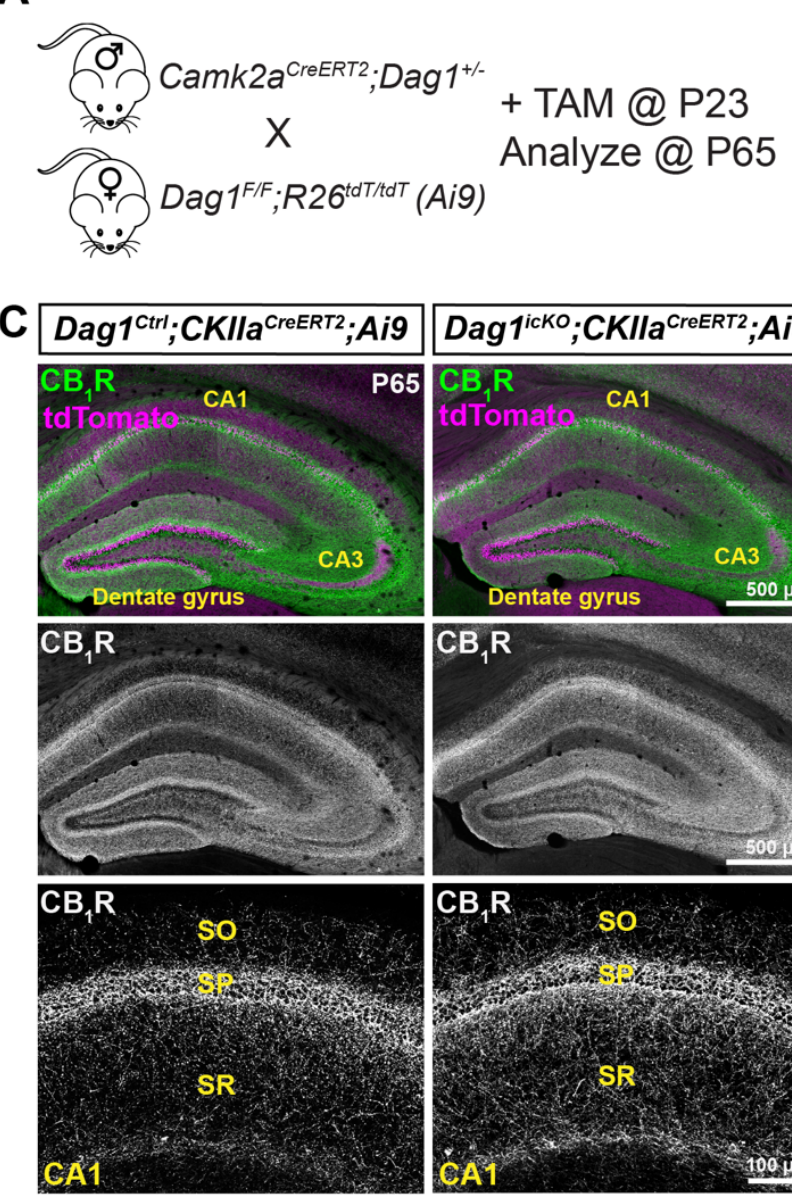
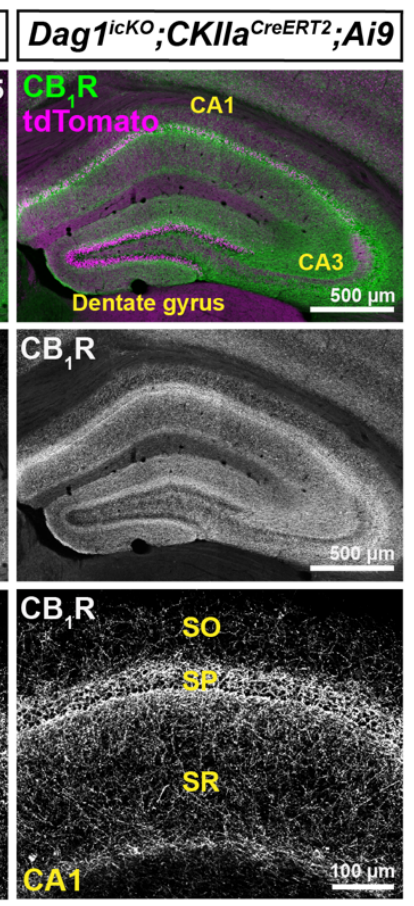
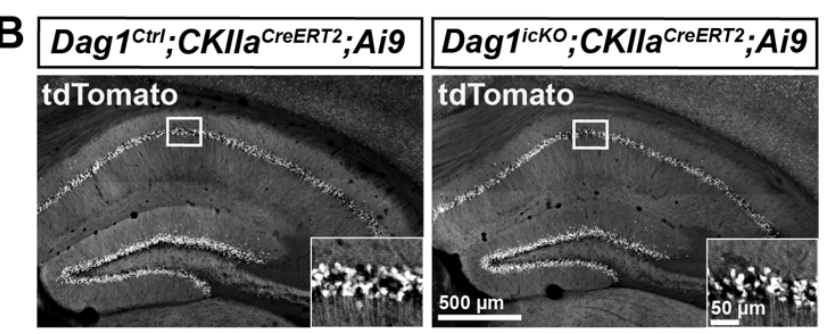

D

$$
\begin{aligned}
& \text { - Dag1 }{ }^{\text {Ctrl }} \text { CKIIlaCreERT2;Ai9 }(\mathrm{n}=3) \\
& \text { - Dagicko;CKIla CreERT2;Ai9 }(\mathrm{n}=3)
\end{aligned}
$$

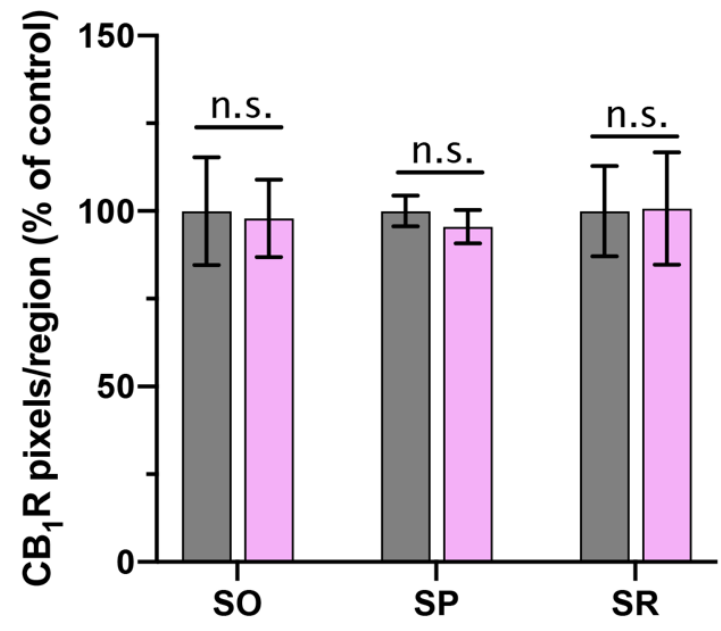

CA1 subregion

Figure 7. Post-developmental maintenance of CCK+ interneurons does not require Dystroglycan. (A) Breeding scheme and experimental approach for generating tamoxifen-inducible Dystroglycan conditional knockout mice. Dag $1^{\text {Ctrl }}$;Camk2a ${ }^{\text {CreERT2;Ai9 }}$

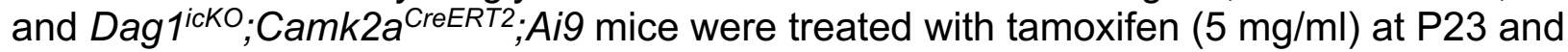
brains were collected for immunohistochemistry six weeks later at P65. (B) Single channel images of tdTomato staining in the hippocampus show the recombination pattern in PyNs. Insets show enlarged view of tdT+ pyramidal neurons in the CA1. (C) Immunostaining for $\mathrm{CB}_{1} \mathrm{R}+$ terminals (green) and tdTomato signal (magenta) in the hippocampus of P65 Dag ${ }^{\text {Ctrl }}$;Camk2a ${ }^{\text {CreERT2 } ; A i 9 ~(l e f t ~ p a n e l s) ~ a n d ~}$ Dag 1icKO;Camk2aCreERT2;Ai9 mice (right panels) shows that the deletion of Dystroglycan in adult PyNs does not affect $C_{1} B_{1} R+$ terminal maintenance. (D) Quantification of $C_{1} R$ pixels in hippocampal CA1 of Dag1 ${ }^{\text {Ctrl }} ;$ Camk2a ${ }^{\text {CreERT2 }} ; A$ Ai9 (gray) and Dag ${ }^{i c K O} ;$ Camk2a ${ }^{C r e E R T 2} ; A i 9$ (pink) mice (n.s. = not significant, unpaired two-tailed Student's t-test; $\mathrm{n}=3$ mice/genotype). Data are presented as mean values \pm s.e.m. Data are normalized to Dag ${ }^{\text {Control }}$ signal in each layer. SO, stratum oriens; SP, stratum pyramidale; SR, stratum radiatum. 


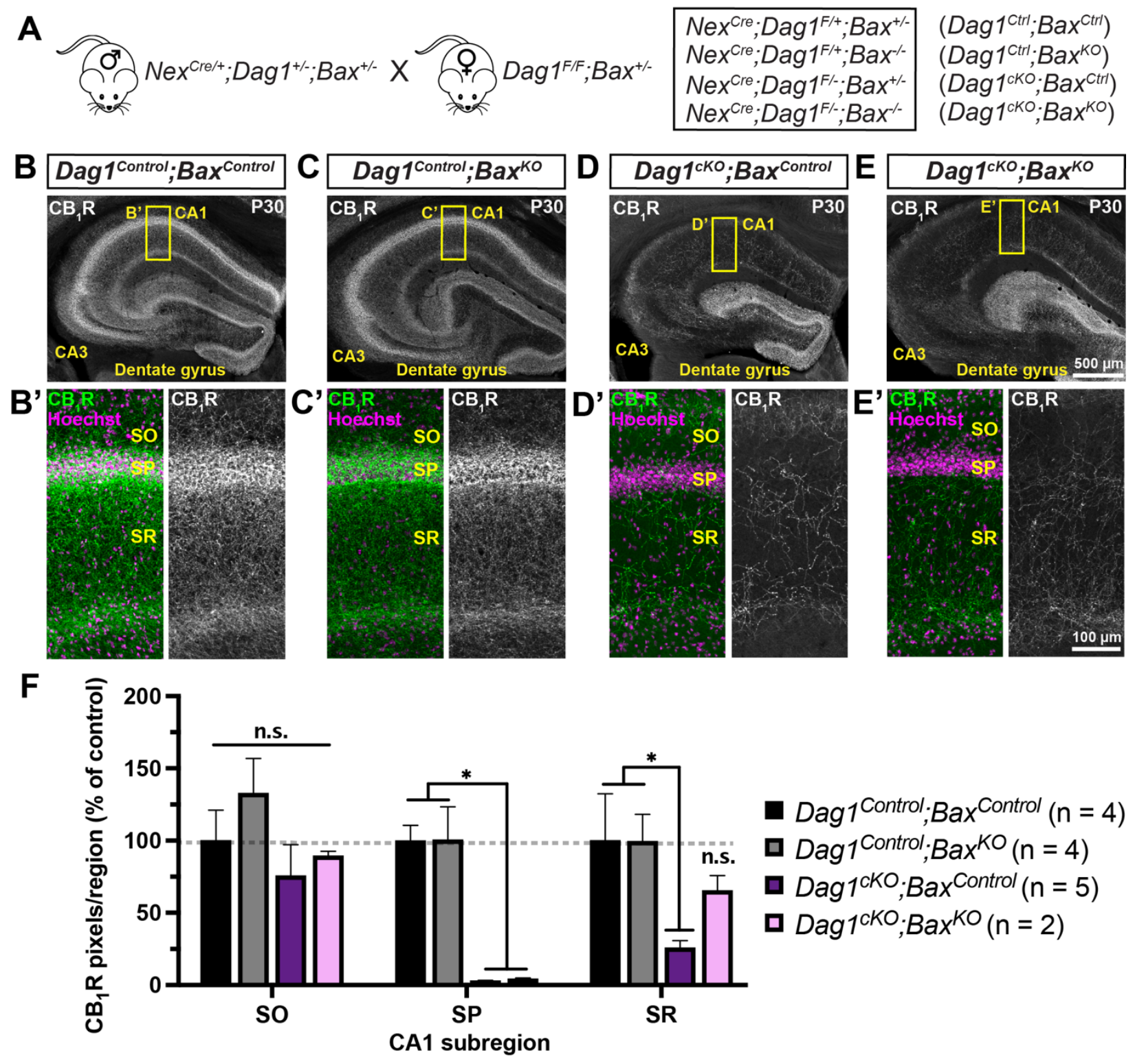

Figure 8. Constitutive deletion of $B a x$ does not rescue $C_{1} B_{1} R+$ terminals in the hippocampus. (A) Breeding scheme for deletion of Bax in Dag $1^{\text {Control }}$ and Dag $1^{\mathrm{KKO}}$ mice; the four genotypes analyzed and their abbreviations are shown to the right. (B-E) Coronal sections of the hippocampus stained for $\mathrm{CB}_{1} \mathrm{R}$ (gray) from (B) Dag $1^{\text {Control;BBax }}{ }^{\text {Control }}$, (C) Dag $1^{\text {Control; }} B \mathrm{Bax}^{\mathrm{KO}}$, (D) Dag ${ }^{\mathrm{CKO}}$;Bax ${ }^{\text {Control }}$ and (E) Dag ${ }^{c K O} ; B a x^{K O}$ mice. (B'-E') Enlarged images of the CA1 (yellow boxed regions) stained for $\mathrm{CB}_{1} \mathrm{R}$ (green; Right, gray single channel images) and Hoechst (magenta). (F) Quantification of $\mathrm{CB}_{1} \mathrm{R}$ pixels in hippocampal CA1 layers from Dag1 ${ }^{\text {Control; }}$ Bax Control (black bars), Dag ${ }^{\text {Control; } B a x^{K O}}$ (gray bars), Dag ${ }^{1 K O} ; B a x^{C o n t r o l}$ (purple bars), and $D a 1^{c K O} ; B{ }^{K O}$ (pink bars) shows that deleting Bax fails to rescue the loss of $C_{1} B_{1} R$ in $\operatorname{Dag}{ }^{1 K K O}$ mice (n.s. = not significant; ${ }^{*} P<0.05$, unpaired two-tailed Student's t-test; $\mathrm{n}=$ 2-5 mice/genotype). Data are presented as mean values \pm s.e.m. Data are normalized 
bioRxiv preprint doi: https://doi.org/10.1101/2021.04.26.441492; this version posted April 26, 2021. The copyright holder for this preprint (which was not certified by peer review) is the author/funder, who has granted bioRxiv a license to display the preprint in perpetuity. It is made available under aCC-BY-NC-ND 4.0 International license.

to $D a g 1^{\text {Control; }}$ Bax ${ }^{\text {Control }}$ signal in each CA1 layer. SO, stratum oriens; SP, stratum pyramidale; $\mathrm{SR}$, stratum radiatum. 

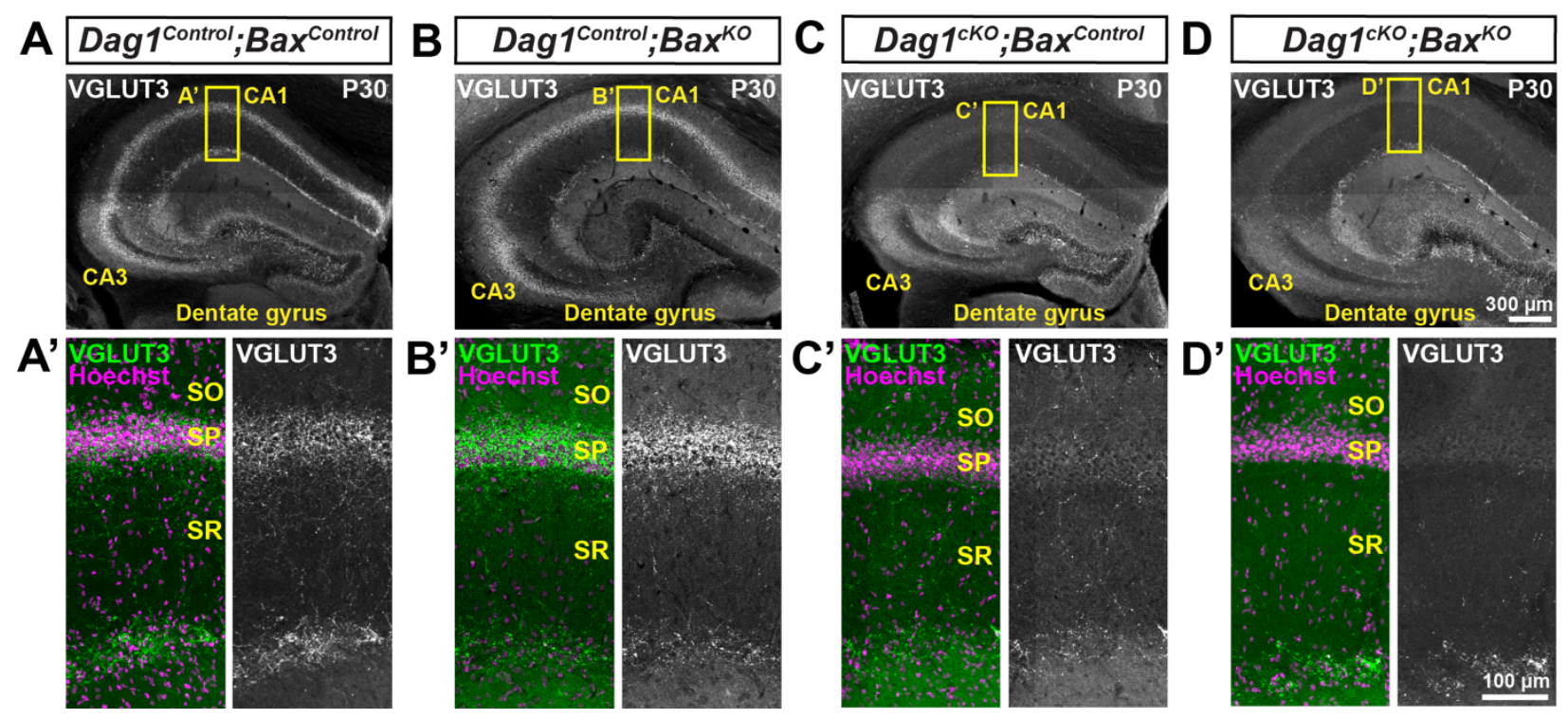

Figure S4. Constitutive deletion of Bax in Dag1 ${ }^{c k o}$ mice does not rescue VGLUT3+ terminals. (A-D) Coronal sections of the hippocampus stained for VGLUT3 (gray) from

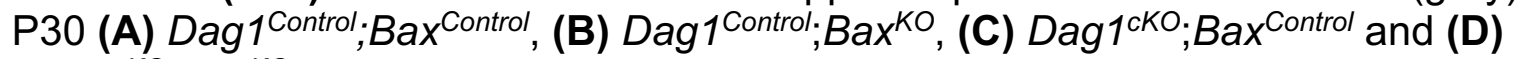
Dag ${ }^{1 K O} ; B a x^{K O}$ mice. (A'-D') Magnified images of the CA1 (yellow boxed regions) stained for VGLUT3 (green; Right, gray single channel images) and Hoechst (magenta) to stain the pyramidal cell layer (SP). SO, stratum oriens; SP, stratum pyramidale; SR, stratum radiatum. 


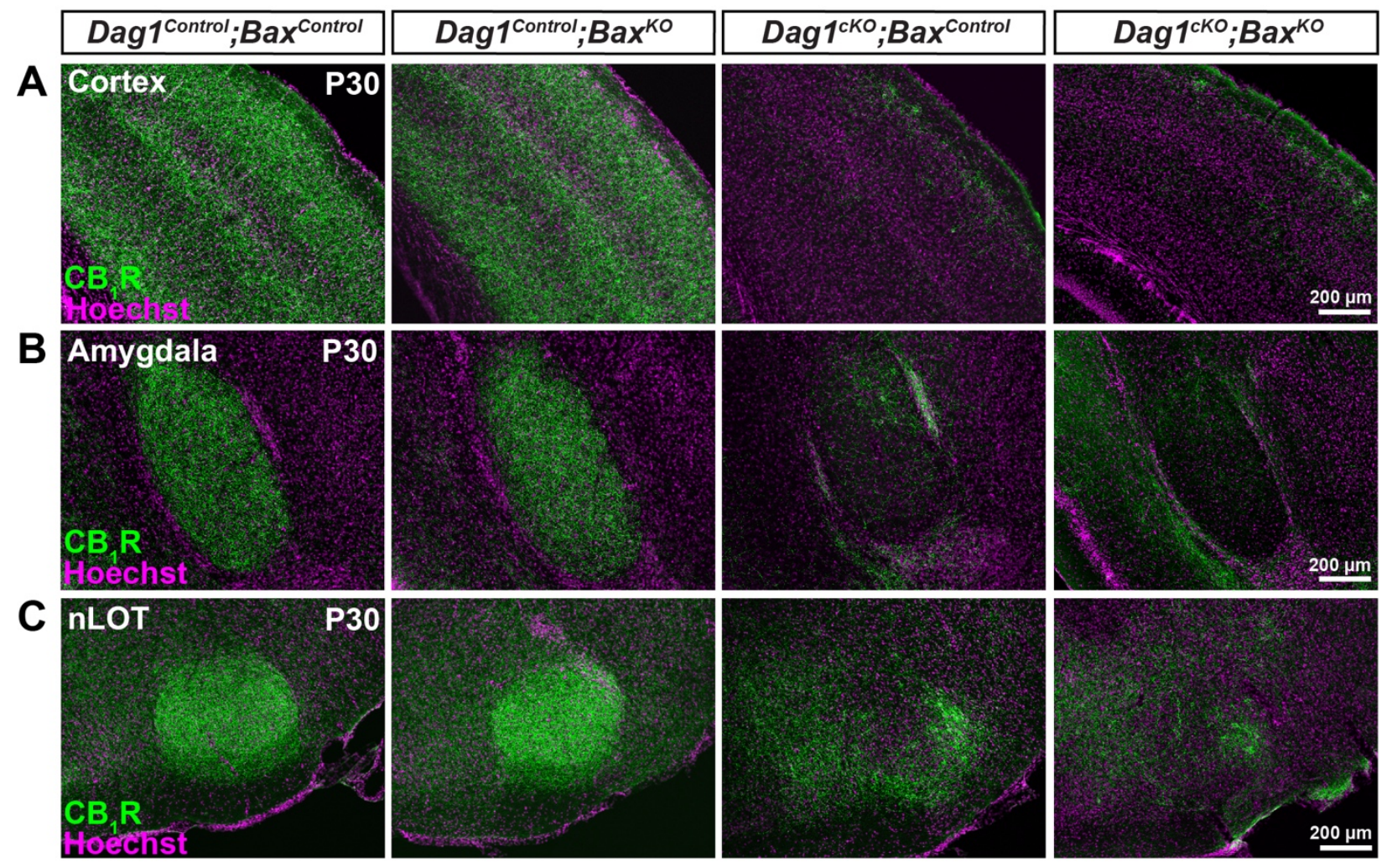

Figure S5. Constitutive deletion of Bax in Dag1cko mice does not rescue $\mathrm{CB}_{1} \mathrm{R+}$ terminals in the forebrain. (A-C) Coronal sections immunostained for $C_{1} R$ (green) and Hoechst (magenta) in the cortex (A), amygdala (B), and nucleus of the lateral

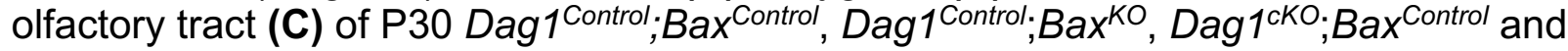
Dag1 ${ }^{\mathrm{CKO}} ; \mathrm{Bax}^{\mathrm{KO}}$ mice. 

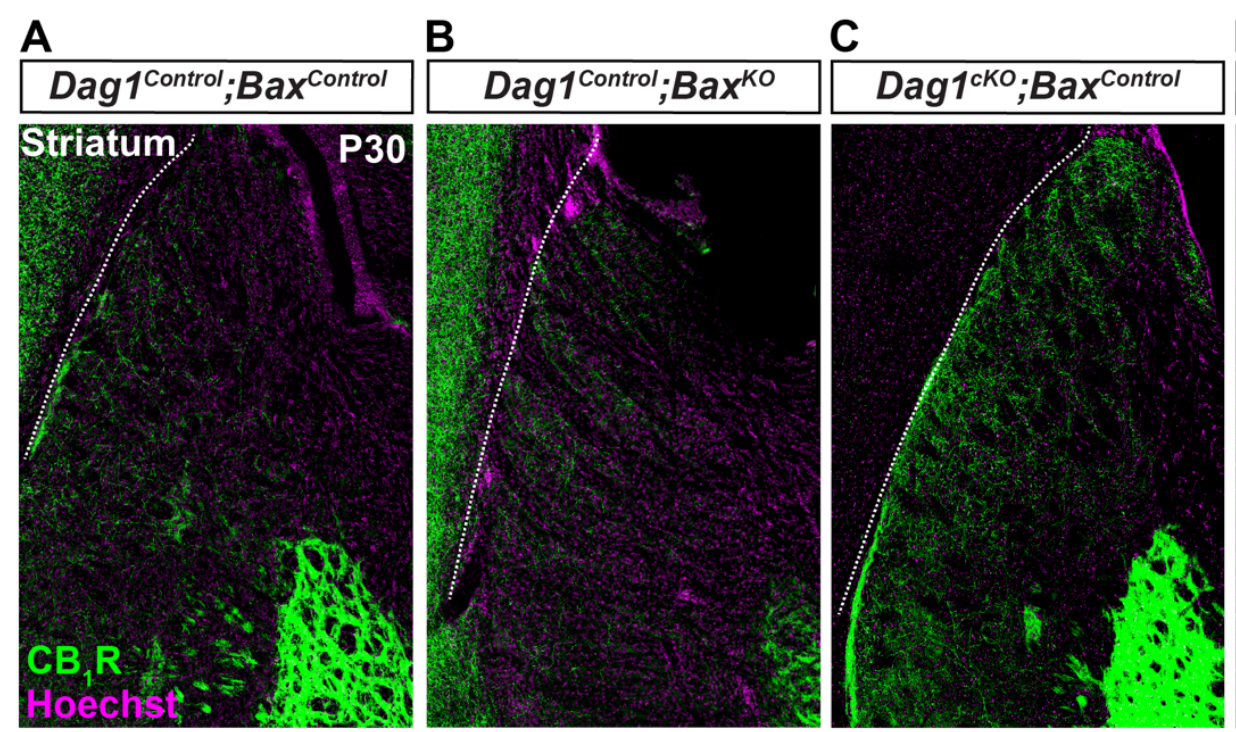

D

E

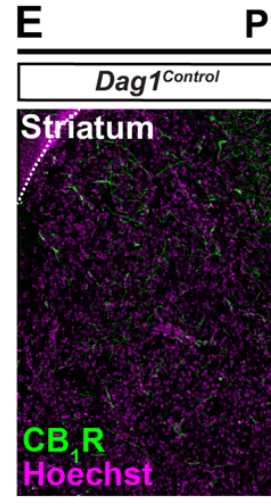

$\mathbf{F}$
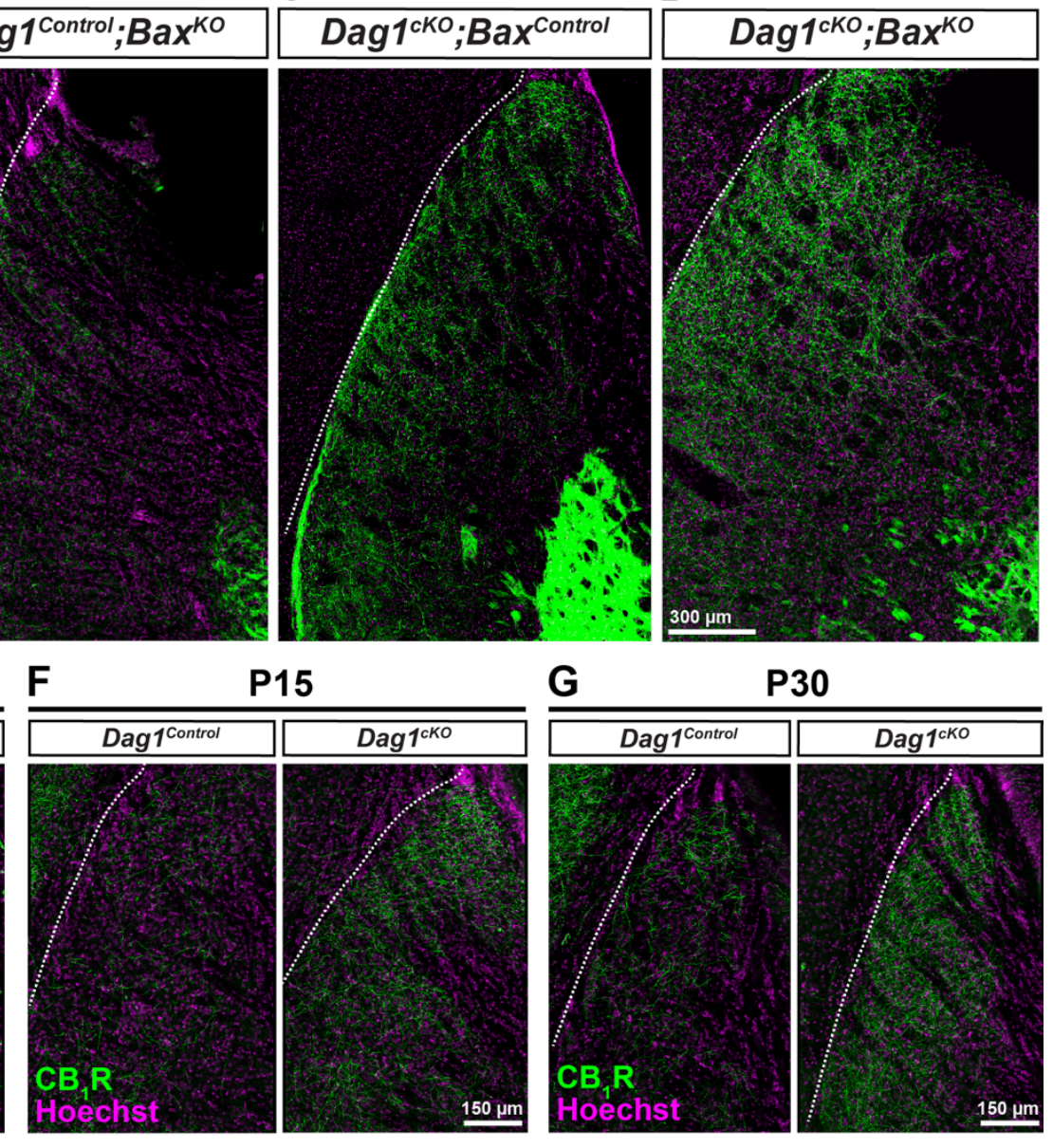

G

P30

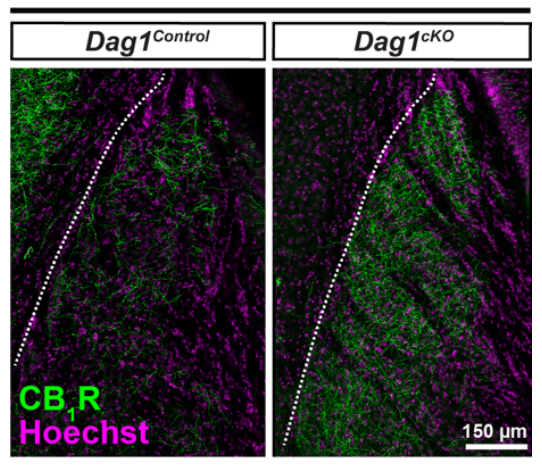

H

$150 \mu \mathrm{m}$
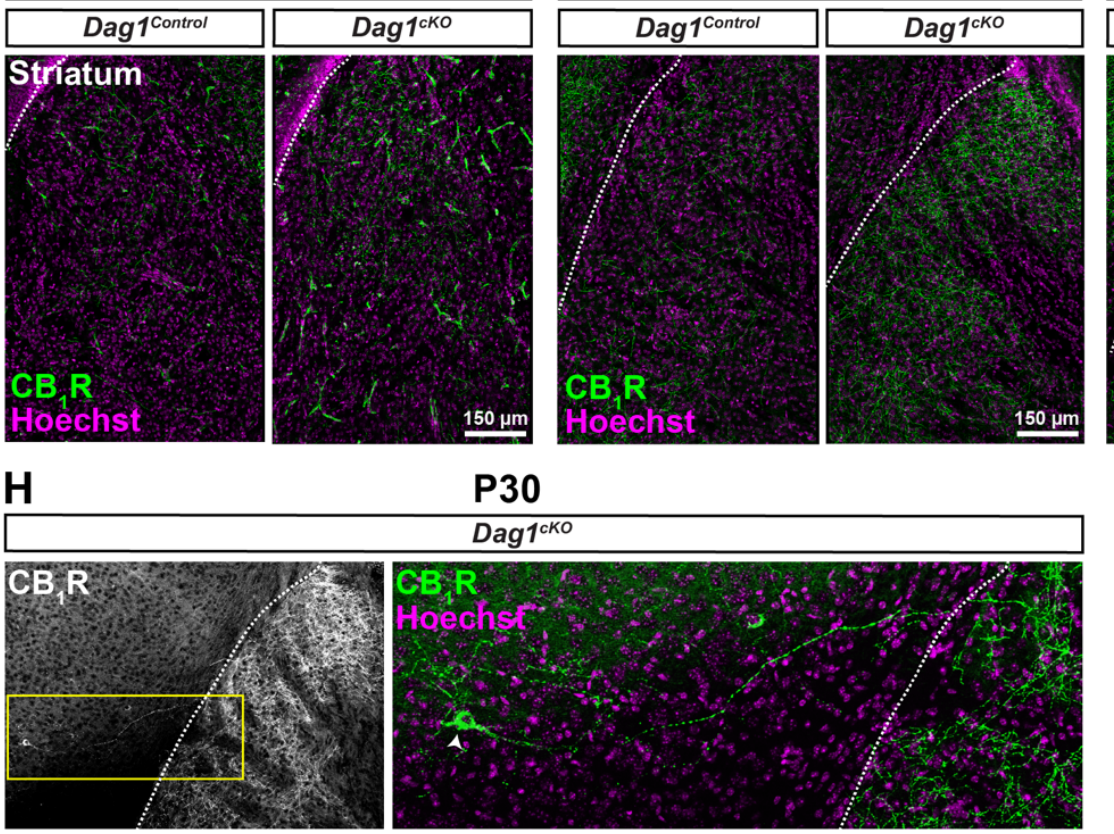

Dag1 ${ }^{\text {cKO }}$
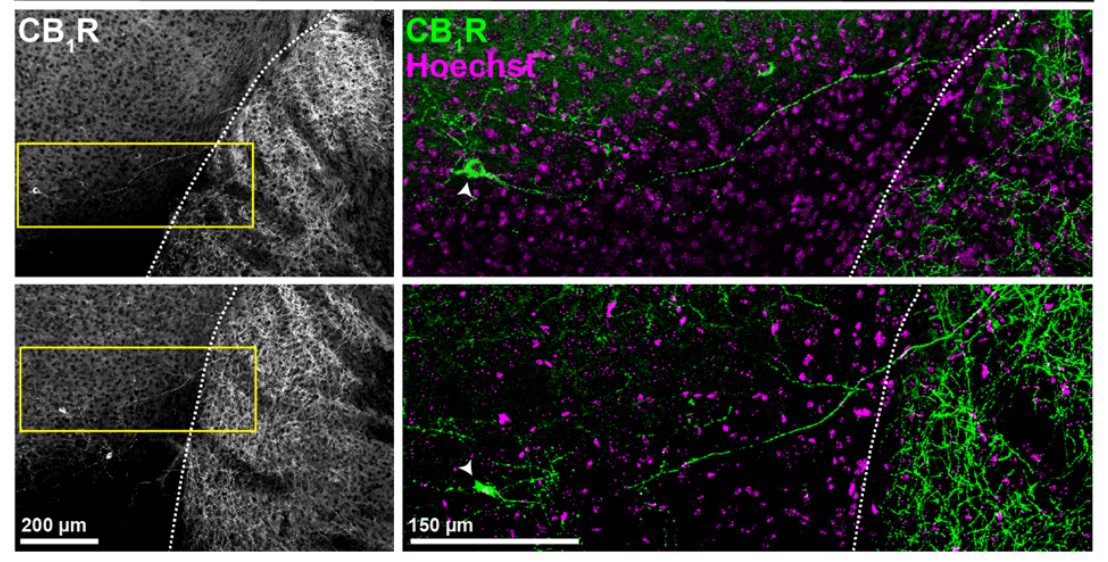

I

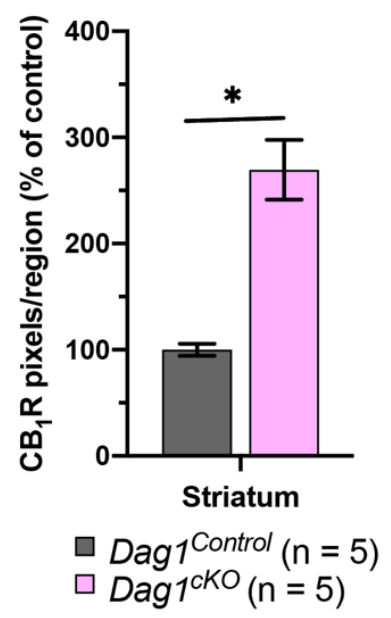

Figure 9. CCK+ interneurons inappropriately innervate the striatum of Dag1cko mice. (A-D) Immunostaining for $\mathrm{CB}_{1} \mathrm{R}$ (green) and Hoechst (magenta) shows minimal $\mathrm{CB}_{1} \mathrm{R}$ innervation in the striatum of $\mathrm{P} 30$ (A) Dag1 ${ }^{\text {Control; }}$ Bax Control and (B)

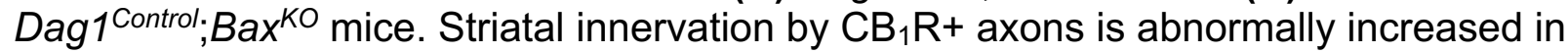
(C) Dag $1^{\text {cKO }} ; B a x^{C o n t r o l}$ and (D) Dag ${ }^{1 K O} ; B a x^{K O}$ mice. (E-G) Immunostaining for $\mathrm{CB}_{1} \mathrm{R}$ (green) and Hoechst (magenta) in the striatum of Dag $1^{\text {Control }}$ and Dag $1^{\text {cKO }}$ mice at P10 
$(E), P 15(F)$, and P30 (G), showing that the inappropriate $C_{1} R$ innervation in the striatum of $D a g 1^{c K O}$ mice increases gradually between P10-P30. $(\mathrm{H})$ Low magnification images (10X) of $\mathrm{CB}_{1} \mathrm{R}+$ cell bodies and their axons (Left panels, gray) near the corticostriatal boundary from two separate $D a g 1^{c K O}$ mice at P30. Yellow boxed regions (right panels) show high magnification (20X) images of individual $\mathrm{CB}_{1} \mathrm{R}+$ cell bodies (arrowheads, green) and their axons projecting from the cortex into the striatum. White dotted lines (A-H) indicate the approximate boundary between the cortex and striatum. (I) Quantification of $\mathrm{CB}_{1} \mathrm{R}$ pixels in the striatum from P30 Dag1 ${ }^{\text {Control }}$ (black bars) and Dag $1^{\text {cKO }}$ (pink bars) mice shows increased $\mathrm{CB}_{1} \mathrm{R}$ staining in Dag $1^{\text {cKO }}\left({ }^{\star} P<0.05\right.$, unpaired two-tailed Student's t-test; $n=5$ mice/genotype). Data are presented as mean values \pm s.e.m. Data are normalized to Dag1 ${ }^{\text {Control }}$ signal. 